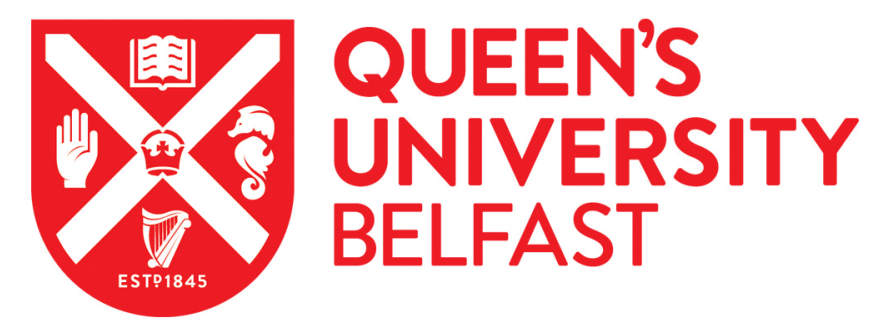

\title{
Evaluating management options for two fisheries that conflict through predator-prey interactions of target species
}

Fitzgerald, C. J., Shephard, S., McLoone, P., Kelly, F., \& Farnsworth, K. D. (2019). Evaluating management options for two fisheries that conflict through predator-prey interactions of target species. Ecological Modelling, 410, [ 108740]. https://doi.org/10.1016/j.ecolmodel.2019.108740

Published in:

Ecological Modelling

Document Version:

Peer reviewed version

Queen's University Belfast - Research Portal:

Link to publication record in Queen's University Belfast Research Portal

Publisher rights

2019 Elsevier B.V. All rights reserved.

This manuscript version is made available under the CC-BY-NC-ND 4.0 license http://creativecommons.org/licenses/by-nc-nd/4.0/,which permits distribution and reproduction for non-commercial purposes, provided the author and source are cited.

\section{General rights}

Copyright for the publications made accessible via the Queen's University Belfast Research Portal is retained by the author(s) and / or other copyright owners and it is a condition of accessing these publications that users recognise and abide by the legal requirements associated with these rights.

Take down policy

The Research Portal is Queen's institutional repository that provides access to Queen's research output. Every effort has been made to ensure that content in the Research Portal does not infringe any person's rights, or applicable UK laws. If you discover content in the Research Portal that you believe breaches copyright or violates any law, please contact openaccess@qub.ac.uk. 


\title{
Evaluating management options for two fisheries that conflict through predator-prey interactions of target species
}

\author{
Colm J. Fitzgerald**1, Samuel Shephard ${ }^{1}$, Paul McLoone ${ }^{1}$, Fiona L. Kelly ${ }^{1}$, and \\ Keith D. Farnsworth ${ }^{2}$ \\ ${ }^{1}$ Inland Fisheries Ireland, 3044 Lake Drive, Citywest, Dublin 24, D24 Y265, \\ Ireland \\ ${ }^{2}$ School of Biological Sciences, Queen's University Belfast, 97 Lisburn Road, \\ Belfast BT9 7BL, UK
}

\begin{abstract}
When one wild species is food for another and both have their hunting enthusiasts, then conflict can arise. This is particularly true and complicated in fishing, where trophic links are strongly influenced by body-size ratios, alternative prey are available, populations are strongly density dependent and all their parameters are hard to quantify. We examine this problem with a specific example of trout-pike interaction in Irish lakes using a multi-species size-structured population model, set within a quantitative management action assessment framework. We use an informal Bayesian uncertainty analysis to account for empirical imprecision and test a range of stakeholder suggested scenarios for management of the pike and trout fisheries, under three different hypotheses about the abundance of non-trout prey availability. Trout fishing always diminished adult trout biomass. Fishing for pike always increased trout biomass but less effectively as biomasses of alternative (to trout) prey increased. Adult pike cannibalism was found to significantly alleviate predation pressure on trout when alternative prey was not plentiful, less so when it was.
\end{abstract}

Keywords: predator-prey interaction; size-based population model; fisheries management; model uncertainty; pike and trout; management action evaluation

${ }^{*}$ Corresponding author, colm.fitzgerald @fisheriesireland.ie 


\section{Introduction}

Fisheries often target species which interact through predator-prey relations which can lead to potentially complex trade-offs in fisheries yield, depending on the range of bodysizes (due to growth) of both predator and prey species (Houle et al., 2013). When additional species (which may be competitors for the prey and alternative prey for the predator) are included, the indirect effects can generate a wide range of outcomes, following any perturbation, as different cohorts of each population interact generating phenomena such as trophic cascades (Frank et al., 2005; Pace et al., 1999) and food-web loops. This makes it impossible to predict the effect of any stock-management intervention without having a suitable model to represent the dynamic interactions. It is well known (e.g. (Larkin, 1979; Smith et al., 1996, Yodzis, 2001; Byström et al., 2007)) that simplistic conjectures, e.g., 'culling the predator will increase yield of the prey species' or 'increasing prey stock will increase predator stock', are unreliable in this situation. Unfortunately, they often become adopted stakeholder positions in the perceived conflict between a fishery for a predator and one for a prey species. Arguments between advocates for each fishery can become heated in the confined arena of a recreational lake-fishery, e.g. Curtis (2018). It is in this context that we developed a quantitative framework, with realistic representations of uncertainty and underlying ecological interactions, to be used for examining management options whereever two or more species interact through predator-prey dynamics. We applied the framework to a case study, in which we assessed management proposals suggested by the stakeholders, and explored how model representations of competing stakeholder beliefs may affect the outcome of the assessments. The case-study involved recreational fisheries in Irish lakes for Northern pike Esox lucius (hereafter "pike") and Brown trout Salmo trutta (hereafter "trout").

Herein, we provide a clear example of this conflicting fisheries phenomenon which demonstrates the way ecological interactions among two fisheries and their associated management goals can be jointly evaluated using a size-structured model for each species and a Bayesian analysis of uncertainty. This practical problem shows several principles of general application in the management of interacting fisheries. The essential ingredients are a) apparent conflict between predator and prey species fisheries, b) the inclusion of (especially invasive) species acting as both alternative prey to the predator and competitors to the fished prey species, c) the potential mitigating effect of cannibalism by predator species and density-dependence (e.g. via stock-recruitment relations) and d) potential influence of environmental change (e.g. eutrophication or climate change) on stock-recruitment, low-trophic level resource abundance and growth and mortality rates. 
The framework consists of a fisheries management scenario risk-assessment: a welldeveloped process that uses simulation to compare the relative effectiveness for achieving management objectives of different management actions while admitting uncertainty in the data and the model itself (Butterworth and Punt, 1999). Such assessments are considered part of the 'traditional approach' to the provision of scientific advice for management measures (Butterworth, 2007). These incorporate many of the elements of a management strategy evaluation (MSE) but lack a feedback element between the management strategy and the operating models and thus cannot be considered as complete MSE (Punt et al., 2016). At the core of the framework is a spatially aggregated model which tracks focal predator and prey populations using single-species length-structured representations (e.g. Sullivan et al., 1990; Punt et al., 2013) which are coupled through a size-based predation model that accounts for the presence of alternative prey (present as part of the aquatic community) via a constant, size-distributed biomass resource. By focusing on the key components of the ecosystem within the context of the management question, the model design follows the principles of best practice for ecosystem models in seeking to find a balance between model complexity and realism subject to constraints imposed by data availability (Collie et al. 2016; Plagányi et al., 2014). Although the model used for our case-study is tailored towards the particular lake ecosystems and management question outlined (as recommended by Hilborn et al. (2017)), the design and exposition is sufficiently general to allow application to similar ecosystems. As we examine management options using the framework, we emphasise the different assumptions made by different stakeholder groups and where there is uncertainty (e.g. over the availability of alternative prey species), we explicitly show the effect of a range of assumptions. The approach adopted is one of facilitating negotiation and selection among management choices through realistic scenario testing.

\section{Methods}

In overall structure, our method comprises a) building a general size-structured model of focal species and their size-dependent interactions, b) specifying this in a particular case with relevant empirical data, including fisheries data, c) subjecting the model to sensitivity and Bayesian uncertainty analysis, d) using it to examine management scenarios (suggested by stakeholders), with quantified uncertainty. Specifically, we examine three stakeholder 'belief' sets (representing trout angler, pike angler and neutral assumptions) in the context of three hypotheses about the abundance of 'alternate' prey for the pike: scarce, moderate and plentiful. The intention is that the resulting nine-way scenario set 
will provide an informative quantitative basis for rational discussions among stakeholders and managers.

\subsection{Study system: social and natural history}

The trout are a highly-regarded recreational angling species in many Irish lakes. In the late 1950s, a number of the larger lakes were designated by the Inland Fisheries Trust as 'wild' brown trout fisheries. The pike are top freshwater piscivores and coexist with trout in several of these systems. Scientific investigations starting in the 1940s attributed apparent deterioration in the quality of trout angling in the designated fisheries primarily to predation by pike (Healy, 1956; Toner, 1959; Kennedy, 1969; Bracken, 1973; Gargan and O'Grady, 1992). Pike culling programmes became a key part of the development of the trout fisheries, and Inland Fisheries Ireland (IFI) continues removals to some degree on certain lakes. The popularity of pike as an angling species has subsequently increased in Ireland, and large pike are prized as trophy fish by recreational anglers across Europe. The designated trout lakes now support valuable recreational fisheries for both trout and pike (IFI, 2015a b), and pike removal as a fisheries management tool has become a heavily contested issue (Curtis, 2018). Many of the designated lakes have shown strong environmental changes in recent decades (Champ, 1998), which may modify the impacts of fish predation (Haught and von Hippel, 2011). Environmental change has facilitated the establishment of non-native roach (Rutilus rutilus) as an abundant alternative prey species for pike (Pedreschi et al., 2015); availability of roach has been shown to change the relationship between pike removal rate and subsequent trout abundance (Shephard et al. 2018). These factors demand formal assessment of the performance of pike removal and other interventions.

The designated trout lakes have considerable economic and societal importance, especially in the west of Ireland, and the issue of pike removal has generated a high degree of local controversy. The extremes of this debate are represented by a minority of trout anglers who favour intense pike culling, and a majority of pike anglers who advocate for total cessation of pike removal. The latter group point out that trout angling pressure is relatively unrestricted on the designated lakes (daily per capita limit of four fish killed), and may be an important pressure on trout populations. A policy review group chaired by IFI provided a forum in which stakeholders have informally suggested various management tools for achieving their favoured fishery objectives. Underlying this range of stakeholder perspectives are different beliefs about how pike and trout interact directly and with other species in the Irish lakes. The suggestions of stakeholders provide a suite 
of candidate management actions; the performance of these actions can be assessed using the size-based model to represent different trout-pike interaction scenarios that correspond to given stakeholder beliefs about the behaviour of these fish Haapasaari et al. 2007). It is worth commenting that the resulting model and management action assessment must be very convincing for them to have a positive effect in this highly contested arena: a situation that will be familiar to many applied ecologists.

\subsection{Model development}

A model is developed to quantify size-resolved population-level interactions between a predator and a prey fish species, where either (or both) species can be harvested. The two fish populations are represented within a wider ecosystem, in which other fish species and lower trophic level organisms are included as potential prey via a resource size-spectrum: i.e. the distribution of biomass across the length or body-mass axis.

\subsubsection{Length-structured single species model}

The core building block of the model is a spatially-aggregated, length-structured representation of population dynamics. In this model, the predator and prey fishes are both assumed to be iteroparous and juvenile recruitment to the adult population is assumed to occur at the same time each year. The influence of temporal and spatial variations in environmental conditions on the populations is neglected. Therefore, we adopt a deterministic, discrete-time description of the dynamics of the interacting populations based on the stage-structured matrix population model approach (Caswell, 2001). Predation and fisheries removals are primarily size-dependent processes and so the predator and prey populations are classified by length (body-mass could also be used, but length data are more readily available). The length-structured population dynamics for each species are governed by the difference equation:

$$
\boldsymbol{N}_{t+1}=\boldsymbol{P S} \boldsymbol{N}_{t}+\boldsymbol{R}_{t+1}
$$

where $\boldsymbol{N}_{t}$ is a vector of fish abundance resolved into $J$ length classes: $n_{j}$ with $j=1 \cdots J$ in year $t$ for the species, $\boldsymbol{P}$ is a $J \times J$ growth transition matrix, $\boldsymbol{S}$ is a $J \times J$ survival matrix and $\boldsymbol{R}_{t+1}$ is a recruitment vector (length $J$ ) containing the abundance of recruits to each length class at the beginning of year $t+1$.

Growth in body length is described at the population level using the stochastic form of the von Bertalanffy model (LVB) von Bertalanffy (1938) adopted by Sullivan et al. 
(1990). Underlying this stochastic LVB growth model are the assumptions that fish may not 'shrink'; only fish that survive from year $t$ to $t+1$ may grow; and fish abundances must be conserved (mortality is separated into the survival term $\boldsymbol{S}$ ). The elements $P_{m, l}$ of the growth transition matrix $\boldsymbol{P}$ in Equation (1) each represent the annual proportion of length class $l$ transitioning to length class $m ; \boldsymbol{P}$ is lower diagonal to satisfy the "no shrinking' rule and fish abundances are conserved only if $\sum_{m} P_{m, l}=1$. In the stochastic LVB approach, growth, hence each $P_{m, l}$, depends on i) the length class interval (width), ii) the deterministic LVB length-at-infinity $L_{\infty}$ and growth rate parameter $k$ and iii) the (random) variance in growth rate among individuals in the population. For simplicity, all individuals were assumed to begin each time increment at the mid-point of their respective length classes and have a mean growth increment equal to that of an individual with mid-class length. That is, the average initial state and growth of fish in each length class is assumed to be well represented by a fish with mid-class length. It is worth noting that more precise, but computationally more difficult, methods have recently become available (Millar and Nottingham, 2018). A gamma distribution was chosen to represent individual variability in the growth increment about the mean because it is sufficiently flexible to represent the positive-skewed nature of growth increments for smaller fish and the narrower distribution of the growth increment for larger, more slowly growing fish (Sullivan et al., 1990). It has also been found to promote robustness and parsimony in a length-structured modelling framework (Drouineau et al., 2008). An important advantage of the gamma distribution is that once its shape parameter is fixed, the mean and variance depend only on the growth constants $L_{\infty}$ and $k$, so it uniquely determines the proportion of individuals transitioning from one class to another. This method and the fixing of the shape parameter are described in detail in Appendix A.1.

The physiological condition of individuals in the population is not tracked within the model. Thus, individual body mass $w$ is related to length through a species-specific allometric weight-length model $w=\alpha L^{\beta}$ and each fish in a particular size class is assumed on average to have a body mass predicted by a fish with mid-class length.

Mortality in the population may occur through natural causes (including predation) and fishery removals: all these population losses are accounted for through the survival matrix in Equation (1). The diagonal elements $S_{l, l}$ of this matrix represent the proportion of surviving fish in length class $l$ over the course of a year. Natural mortality $(M)$ and fishing mortality $(F)$ are assumed to act continuously and concurrently throughout the year so that the annual survivorship for individuals in length class $l$ is calculated as

$$
S_{l, l}=\exp \left(-Z_{l}\right)
$$


where $Z_{l}=M_{l}+F_{l}$ is the total mortality composed of length-class specific natural $M_{l}$ and fishing $F_{l}$ contributions.

Natural mortality is widely accepted to vary over size and age (cf. e.g. Beyer, 1989 , Gislason et al. 2010). In stock assessment (and projection), it was conventionally assumed to be constant over much of the exploited life span and size range of a population, but that assumption is now regarded as misleading, especially for multi-species models (e.g. MSVPA Helgason and Gislason (1979); Pope (1979)) and for the present purpose is considered inadequate. Here we decompose natural mortality into size-dependent predation and residual (background) components $M_{l}=D+Q_{l}$ following Gislason and Helgason (1985). Estimates for the constant residual mortality $D$ may be obtained from one of myriad empirical methods developed to determine point values of natural mortality based on other directly estimated life history parameters. Of the methods predicated on LVB growth parameters, Then et al. (2015) recommend the use of the improved form of the growth-based estimator derived by (Hoenig, 1983), i.e.,

$$
D_{\text {est }}=4.118 K^{0.73} L_{\infty}^{-0.33}
$$

This estimator gives the residual mortality $D$ for adult top predators that experience little or no interspecific predation. However, mortality estimator (3) may indirectly incorporate predation effects for prey species. In order to avoid accounting for predation twice in natural mortality, residual prey mortality is assumed to take a value of between $50 \%$ and $100 \%$ (point estimate of $75 \%$ ) of the empirical estimator prediction $D_{\text {est }}$.

Predation mortality rates of aquatic animals typically decline with increasing prey size classes (Beyer, 1989), consistent with the size-based theory of community dynamics Andersen et al. (2016), which we take up shortly (the size-based theory is central to the predator-prey model described in the next sections).

Fisheries removals are represented through a length-specific, instantaneous fishing mortality rate as

$$
F_{l, t}=F_{t} s_{l}
$$

where $F_{t}$ is a (possibly time-dependent) fishing mortality for fully vulnerable fish (related to effort) and $s_{l}$ denotes the vulnerability of fish in length class $l$ to the fishery (analogous to the 'catchability' of net fisheries). Vulnerability $s_{l}$ ranges from zero to one and can be empirically estimated for each length class $l$, taking account of the fishery size regulations (it may depend on specific lake / fishery characteristics). A simple linear interpolation is adopted to estimate vulnerability of fish in a length-class spanning a minimum or maximum length regulation. 
Population regeneration is modelled through a spawner-recruitment or 'stock-recruitment' (SR) relationship which describes how juvenile recruitment to a certain age is related to adult spawning stock $Y$, which may be measured in terms of egg deposition, spawning stock biomass (SSB), adult abundance, or other spawner abundance proxies. Stockrecruitment models are of fundamental importance in long-term projections of fish population dynamics and to likely outcomes of fisheries management strategies Myers and Barrowman, 1996; Needle, 2001, Quinn II and Deriso, 1999). Environmental influences, represented through stochastic recruitment variability, are neglected in this deterministic description of population dynamics.

Juvenile recruitment to the adult predator and prey populations occurs at the start of each year $t+1$ and the abundance of recruits $R$ is assumed to depend on the spawning stock $Y$ in year $t+1-a_{r}$, where $a_{r}$ denotes the average age at recruitment. Spawning stock $Y$ is calculated from the length-specific abundances as:

$$
Y=\sum_{l} f_{l} N_{l, t+1-a_{r}}
$$

where $f_{l}$ transforms the abundance in class $l$ to the appropriate spawning stock contribution. For example, if spawning stock is expressed in terms of egg deposition then $f_{l}$ correspond to length-specific adult fecundity. Juveniles are assumed to recruit to length class $l$ with fixed proportions $p_{l}$ every year, as is typical in length-structured models (Punt et al. 2013), so that recruitment by length class is

$$
R_{l, t+1}=p_{l} f\left(Y\left(\boldsymbol{N}_{t+1-a_{r}}\right)\right)
$$

where $f(Y)$ is the functional form of the stock-recruit relationship and $Y\left(\boldsymbol{N}_{t+1-a_{r}}\right)$ denotes the spawning stock dependence on the vector of adult abundances. Effects of density dependence are most naturally expressed by formulating the SR relationship in terms of spawning stock density (spawning stock relative to spawning habitat area). The exact form of the SR relationship should reflect the biological characteristics of the modelled species and may differ for target predator and prey species. Classical SR models such as those derived by Beverton and Holt (1957) and Ricker (1954) are employed where possible although other well-established elaborations (see Quinn II and Deriso, 1999 , for a review of classic SR models) may also be used where appropriate. 


\subsubsection{Linking populations through size-dependent predator-prey relations}

Multi-species models of fish communities describe the dynamics of individual species of interest in the community and the interactions between species. Interspecific interactions within fish communities primarily occur through predation and resource competition. Predation is represented in multi-species models by the introduction of an added predation mortality term for all prey species or prey classes (Helgason and Gislason, 1979; Pope, 1979; Gislason and Helgason, 1985; Punt and Butterworth, 1995; Speirs et al. 2010). It is relatively straightforward to derive an expression for the predation mortality rate based on biomass conservation principles however the exact formulation will differ depending on the population structuring and assumed predator functional response (Garrison et al., 2010). In contrast, resource competition between fish species is far more difficult to represent in a multi-species model context because it requires knowledge of the underlying resource, i.e. organisms at lower trophic levels such as macroinverterbrates and zooplankton, and the effects of resource scarcity on competitors. Butterworth and Plagányi (2004) noted that ecosystem or multi-species models are more likely to achieve reliable predictive ability for top predators and their prey for this reason: intermediate species in the food chain have multiple complex linkages with other trophic levels that are difficult to represent mechanistically. The minimum realistic model described herein is developed to represent population-level interactions between a top fish predator and a single prey species, both of which are subject to different fisheries, by accounting for predation only.

Most piscivorous fish are gape-limited predators and outcomes of individual predatorprey encounters are primarily determined by predator gape dimensions and prey body depth both for which body length serves as an effective proxy. A length-structured formulation of the single-species dynamics of the focal predator and prey populations was adopted precisely because it provides a natural context for the inclusion of predationbased species interaction. In a size-structured model all individuals in a particular population size class are expected to respond to their environment in the same way on average (Caswell, 2001) as predicted by that size variable (e.g., length). Thus, a multi-species model is constructed by dynamically linking single-species length-structured models, formulated as in Equation (1), through a predation mortality term dependent on the predator and prey lengths, population length-structures and other prey size-structure.

A predation sub-model similar to that developed by Gislason and Helgason (1985) (for the multi-species virtual population analysis (MSVPA) (Sparre, 1991; Vinther, 2001; Magnusson et al., 2013)) and to the elaboration developed by Speirs et al. (2010) is 
adopted to determine the predation mortality rates for each prey class. These multispecies predation theories assume predator food rations are always satisfied, irrespective of prey abundance, and are categorized as "efficient predator models" or "constant ration models" (Butterworth and Plagányi, 2004). This restricts the model application to ecosystems where the predator is not food-limited. This is a reasonable assumption for those designated Irish trout fisheries where the predator (pike) populations are controlled by management removals and/or are limited by availability of suitable spawning habitat area. Careful consideration should be given to the ecological factors that may affect predator population dynamics prior to model application in order to avoid violation of key model assumptions. In addition to the constant predator ration assumption, we also assume that the predator consumes its prey in proportion to the "suitable" or "available" prey biomass. The concept of suitability (Andersen and Ursin, 1977) was introduced to represent the prey environment as perceived by a particular predator and is defined as the fraction of potential biomass in the environment available to a predator. Hereafter, the term available prey is preferred. This fraction is obtained by combining standardised measures of predator-prey habitat overlap, prey species vulnerability, and prey size preference.

In a large aquatic ecosystem, the potential food for a predator fish species will include a range of prey fish from the fish assemblage and prey organisms at lower trophic levels. Therefore, some representation of the wider fish assemblage and other prey organisms is necessary in a minimum realistic model of a two-species predator-prey interaction in a large waterbody. Following Speirs et al. (2010), a biomass size-spectrum representation of the other food resource (comprising non-target prey species and other organisms) is introduced. Biomass size-spectra define the distribution of biomass over individual organism body-mass $w$ through a simple two-parameter power-law relationship:

$$
B(w)=\kappa_{c} w^{1-\lambda}
$$

Size spectra summarise myriad biological and ecological information in a relatively simple form and have well established empirical (Sheldon and Parsons, 1967; Sweeting et al., 2009: Emmrich et al., 2011) and theoretical (Andersen and Beyer, 2006; Andersen et al., 2016 ; Guiet et al., 2016) foundations. Size-spectrum theory assumes that organism size is the key determinant governing biological processes and organism interactions in an aquatic context, i.e. the trophic level of an individual depends primarily on body-size, not on species. In common with most models of this kind (reviewed by Andersen et al., 2016)), ours here includes a constant (insensitive to consumption) 'background 
resource' biomass size spectrum to represent potential prey biomass other than that of the explicitly modelled species. The background size spectrum serves as a food resource especially for the smaller fish which do not feed on explicitly modelled species, so includes invertebrates and other biological particles as well as species not explicitly accounted for.

Piscivorous top predators show a strong tendency and, in some cases, preference towards cannibalism (Byström et al., 2013). Cannibalism is a size-dependent predation process in which predator and prey belong to the same population (Claessen et al., 2004) and has been observed to occur in both marine fish species (Link et al., 2012) and freshwater fish species (Persson et al. 2000). Cannibalism of juveniles by adults may be represented in the SR relationship (Ricker, 1954, Link et al., 2012) whereas cannibalism of adults requires the inclusion of predator biomass as potential food for the predator. If predator biomass is removed by (intraspecific) predation then a corresponding intraspecific mortality term for each predator length class must be introduced to preserve the conservation of biomass.

Interspecific and intraspecific predation mortality rates are derived from conservation of biomass flux considerations. The annual rate of biomass loss from a particular population length class must equal the fraction of the total food consumption of all predators met by that class. Adopting notation similar to that of Speirs et al. (2010), the balance of biomass loss from prey population $i$ and biomass consumption by predator population $j$ is expressed as

$$
Q_{l}^{(i)} w_{l}^{(i)} N_{l}^{(i)}=\sum_{j} \sum_{m} c_{m}^{(j)} w_{m}^{(j)} N_{m}^{(j)} \Psi_{i l, j m} \quad \text { where } i=1, \ldots, n_{\text {prey }} \text { and } m=1, \ldots, J_{i}
$$

where superscripts $(i)$ and $(j)$ denote predator- and prey-species specific quantities. Thus, $Q_{l}^{(i)}, w_{l}^{(i)}$ and $N_{l}^{(i)}$ denote predation mortality rates, individual body-mass and abundances of prey individuals in length class $l$ of population $i ; c_{m}^{(j)}$ denotes the specific annual food consumption of a predator in length-class $m$ from population $j ; \Psi_{i l, j m}$ is the fractional contribution of prey class $l$ of population $i$ to the diet of length-class $m$ of predator $j$, and $J_{i}$ is the number of length classes structuring prey population $i$. The left-hand side of Equation (8) represents the biomass loss from prey class $m$ and the right-hand side, comprising the product of the overall prey biomass consumed by predators $j$, length class $m\left(c_{m}^{(j)} \times w_{m}^{(j)} N_{m}^{(j)}\right)$ and the fraction of prey class $l$ available to meet predator demand $\left(\Psi_{i l, j n}\right)$ summed across all predator length classes, represents biomass consumption of that prey class by all predators.

The 'dietary composition fraction' $\Psi_{i l, j m}$ is assumed to equal the proportional en- 
counter rate incorporating prey availability, i.e., prey are consumed in proportion to their biomass 'availability'. The available biomass of prey is the (weighted) fraction of total potential prey taking account of predator prey size- and species-selectivity and predator-prey habitat overlap. Other predator functional responses may be used in a multi-species models (Hunsicker et al., 2011) but this simple response is plausible for most prey abundances. Thus, the predator's dietary composition term is calculated as

$$
\Psi_{i l, j m}=\frac{G_{i l, j m} w_{l}^{(i)} N_{l}^{(i)}}{\sum_{i} \sum_{k} G_{i k, j m} w_{k}^{(i)} N_{k}^{(i)}+\int G_{j m}(w) B(w) d w},
$$

where $G_{i l, j m}$ is the fraction of the biomass of prey class $l$ in population $i$ available or accessible to predator species $j$, class $m$ and similarly $\int G_{j n}(w) B(w) d w$ is the available fraction of other prey biomass $\int B(w) d w$. The denominator in Equation (9), which equals the total available food for predators in size class $m$, includes a sum over length classes $\left(\sum_{k}\right)$ within a sum over prey species $\left(\sum_{i}\right)$.

The particular ecosystem modelled herein features one focal, possibly cannibalistic, predator population/species, one focal prey species and an alternative prey biomass. Thus, the length classes of both the focal predator $(i=1)$ and focal prey $(i=2)$ populations are treated as potential food for the predator. Therefore, the predation mortality rate for length class $l$ of prey population $i$ in an ecosystem with one predator species only is calculated as

$$
Q_{l}^{(i)}=\frac{1}{w_{l}^{(i)} N_{l}^{(i)}} \sum_{m} c_{m}^{(1)} w_{m}^{(1)} N_{m}^{(1)} \Psi_{i l, 1 m}, \quad \text { for } i=1,2
$$

where superscript/subscript 1 denotes the predator species. This mortality term is added to residual natural mortality and fishing mortality when calculating annual survivorship of each population. The coupled, length-structured dynamics of the predator and prey populations are formulated as

$$
\begin{aligned}
& N_{m, t+1}^{(1)}=\sum_{l=1}^{J_{1}} P_{m, l}^{(1)} \exp \left(-\left(D^{(1)}+Q_{l, t}^{(1)}+F_{l, t}^{(1)}\right)\right) N_{l, t}^{(1)}+R_{m, t+1}^{(1)}, \quad m=1, \ldots, J_{1}, \\
& N_{m, t+1}^{(2)}=\sum_{l=1}^{J_{2}} P_{m, l}^{(2)} \exp \left(-\left(D^{(2)}+Q_{l, t}^{(2)}+F_{l, t}^{(2)}\right)\right) N_{l, t}^{(2)}+R_{m, t+1}^{(2)}, \quad m=1, \ldots, J_{2},
\end{aligned}
$$

where predation mortality $Q_{l, t}^{(i)}$ depends on predator and prey abundances in year $t$, as defined in Equation (10). This size-based model is represented in schematic form in 


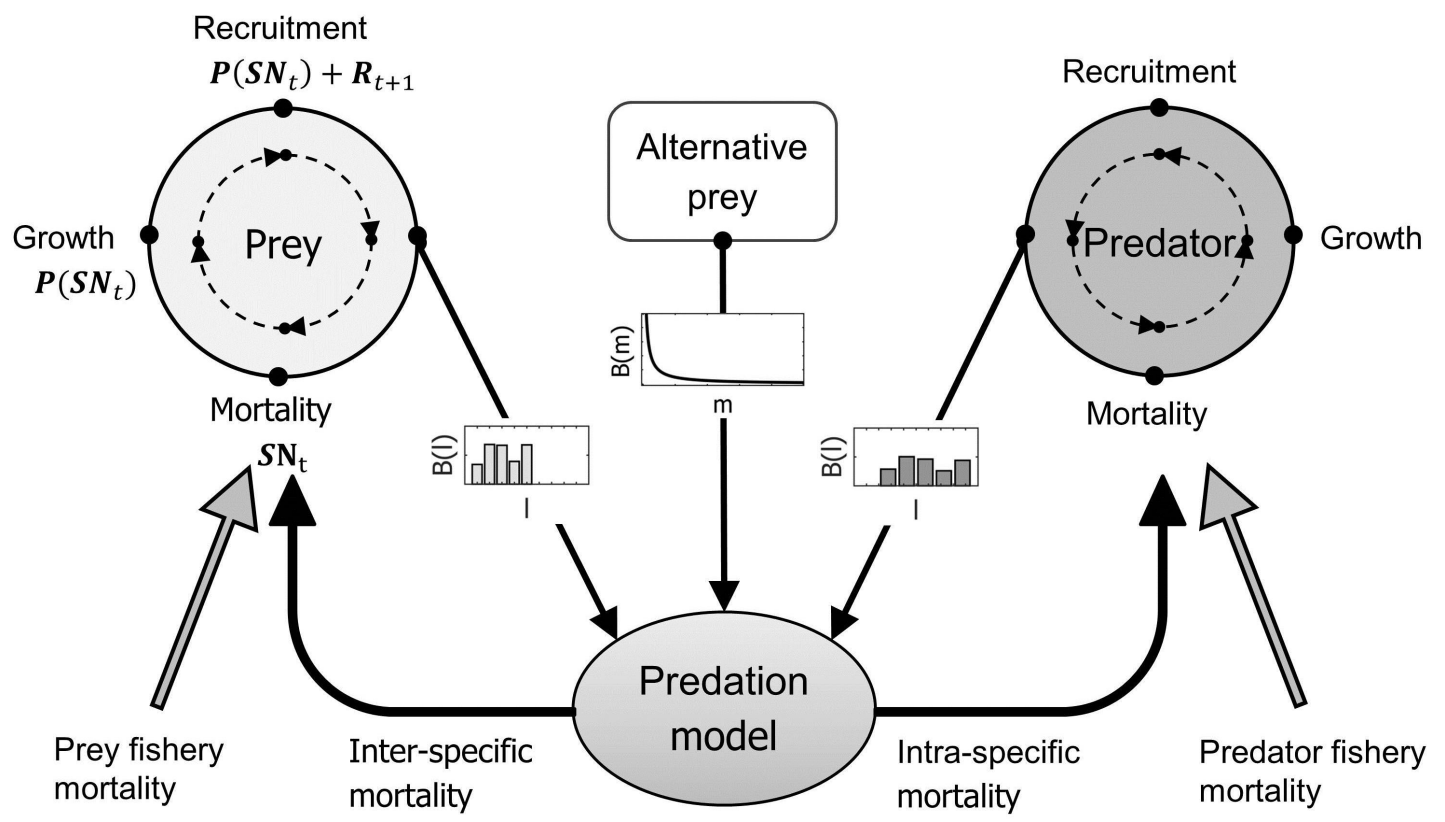

Figure 1: Schematic representation of the size-structured multispecies model. Key predator and prey populations are dynamic (updated every time-step, hence cyclic) and lengthstructured (bar graphs) whereas the alternative prey resource has a constant biomass distribution. These are used to calculate predation rates (thin arrows indicate information flow). Predation pressure on the predator and prey populations is calculated based on the biomasses of predator, prey and alternative prey at the start of each time step (thick arrows).

Figure 1.

\subsubsection{Accessibility of prey}

The fraction $G_{i l, j m}$ of prey biomass accessible to a predator is important in determining that predator's dietary composition (Equation 9) and was introduced to represent the average prey environment experienced by a predator on the spatial scale of the entire population. Gislason and Helgason (1985) defined this fraction as the product of three independent factors: habitat overlap, prey vulnerability and predator-prey size preference. In an ecosystem with one predator species (denoted $j=1$ ), the accessibility fraction is

$$
G_{i j, 1 m}=\rho_{i} \sigma_{i} g\left(\ell_{i, l}, \ell_{1, m}\right)
$$


where $\sigma_{i}$ denotes predator-prey habitat overlap (proportion of habitat shared in common), $\rho_{i}$ denotes vulnerability of prey species $i$ to the predator species, and $g\left(\ell_{i, l}, \ell_{1, m}\right)$ measures the preference of a predator of size $\ell_{1, m}$ for prey of size $\ell_{i, l}$. Each factor lies in the range $(0,1)$ and so can be interpreted as an independent probability: $\sigma_{i}$ represents an abundance-independent encounter probability, $\rho_{i}$ represents a species-dependent, sizeindependent probability of consumption, and $g\left(\ell_{i, l}, \ell_{1, m}\right)$ represents a size-dependent probability of consumption (the size-preference function).

A size-based preference function represents the hypothesised preference for prey of certain sizes demonstrated by a predator. Various functional forms have been adopted in multi-species models Andersen and Ursin, 1977; Gislason and Helgason, 1985; Speirs et al. 2010; Houle et al., 2013) and stomach content analyses (Floeter and Temming, $2003,2005)$. Andersen and Ursin (1977) proposed, and Gislason and Helgason (1985) and other MSVPA implementations adopted, a lognormal-like selection function

$$
g\left(\ell, \ell_{p}\right)=\exp \left(-\frac{\log \left(\ell_{p} / \ell \beta_{\ell}\right)^{2}}{2 \sigma_{\ell}^{2}}\right)
$$

where $\ell_{p}$ and $\ell$ are the size of predator and prey respectively, $\beta_{\ell}$ is the optimal predatorprey size ratio and $\sigma_{\ell}$ quantifies predator tolerance for variations in the size ratio around the optimal value. The individual fish size metric $\ell$ can be either length or bodymass. For example, the integral over the size spectrum representing other prey biomass in Equation (9) requires evaluation of $G_{1 m}(w)=\rho_{X} \sigma_{X} g\left(w, w_{1 m}\right)$ where subscript $X$ denotes other prey, $w$ is the individual body-mass of other prey, and $w_{1 m}$ represents body-mass for predators in size class $m$. The corresponding length-based weighting of focal prey species biomass $g\left(\ell_{i, l}, \ell_{1, m}\right)$ (or $g_{i l, 1 m}$ in compact notation) in Equation (12) is obtained by evaluating the selection function (13) at the mid-point of the predator and prey length class intervals.

Certain prey species in a fish community may be more vulnerable to a shared predator independent of the influence of habitat overlap and size. Differences in prey species vulnerability may be caused by physiological differences such as body depth or protective spines (Hoogland et al., 1956; Nilsson and Brönmark, 2000) or behavioural anti-predator defence strategies such as shoaling. If all prey in a fish community are equally vulnerable to a predator then vulnerabilities $\rho_{i}$ are equal for all prey populations $i$. Prey vulnerability to a common predator is perhaps better expressed in relative terms, e.g. prey species $i$ is $q_{i} \equiv \rho_{i} / \rho_{X}$ times as vulnerable to the predator as other fish prey $X$. Herein, we standardise prey population vulnerability to the predator using the vulnerability of alternative prey $\rho_{X}$. Therefore, the proportion of individuals of prey species $i$ and class 
$l$ in the diet of predators of length class $m$ from species $j=1$ is

$$
\Psi_{i l, 1 m}=\frac{q_{i} \sigma_{i} g_{i l, 1 m} w_{m}^{(i)} N_{m}^{(i)}}{q_{1} \sigma_{1} \sum_{k} g_{1 k, 1 m} w_{k}^{(1)} N_{k}^{(1)}+q_{2} \sigma_{2} \sum_{k} g_{2 k, 1 m} w_{k}^{(2)} N_{k}^{(2)}+\sigma_{X} \int g\left(w, w_{1 m}\right) B(w) d w},
$$

where $q_{1}$ and $q_{2}$ are the respective vulnerabilities of the predator and prey species to predation relative to the vulnerability of other prey $X$ and $\sigma_{X}$ is the habitat overlap between the predator species and other prey.

Habitat overlap may be quantified from spatial fish stock survey information or estimated based on expert judgment. In lake ecosystems with low spatial heterogeneity, a preliminary approach would be to assume habitat overlap is identical for all prey and predator combinations. However, if data or observations suggest strong spatial (or temporal) niche structuring of the fish community then such information should be incorporated in the model through appropriate habitat overlap parameter estimation for each predator-prey combination.

\subsection{Case study — pike and trout in Irish lakes}

A demonstration of the size-structured model of predator-prey interactions described in Section 2.2 was conducted for pike and trout populations on Lough Conn (County Mayo, in the northwest of Ireland), one of the designated Irish wild brown trout lake fishery whereon pike removal operations continue. This lake was selected as the particular lake fishery because of the availability of pike dietary data (McLoone et al. 2019) and annual total catch data spanning 1978-2001, which has been used to estimate absolute biomass of catchable trout stocks on the lake (Fitzgerald et al., 2018). Accurate model representation of the pike-trout interactions in a specific lake requires careful parameterisation of the model based on ecological and biological data available for that system. Model parameters were estimated either from data directly sampled from the population or ecosystem, through inferences from data sampled from other populations, species or ecosystems or through expert judgement if data were absent (for example, see Tables 1-4. Such parameter estimates are inherently uncertain because of variability and incompleteness of data and the propagation of this uncertainty through to model projections is explored in later sections. The methods for estimating parameters from data are described next with further details in Appendix $\mathrm{A}$. 


\begin{tabular}{|c|c|c|c|}
\hline Description & Notation & Source of data & $\begin{array}{l}\text { Point estimate } \\
\text { (s) }\end{array}$ \\
\hline LVB length-at-infinity & $L_{\infty}$ & Kelly et al. (2017) & $50.5 \mathrm{~cm}$ \\
\hline LVB growth constant & $k$ & Kelly et al. (2017) & $0.25 \mathrm{yr}^{-1}$ \\
\hline $\begin{array}{l}\text { Length-body-mass re- } \\
\text { gression }\end{array}$ & $(\alpha, \beta)$ & Kelly et al. (2017) & $\begin{array}{l}(\exp (-4.44) \\
2.98)\end{array}$ \\
\hline $\begin{array}{l}\text { Residual natural mor- } \\
\text { tality }\end{array}$ & $D$ & $\begin{array}{l}\text { Discounted Then et al. } \\
(2015), L_{\infty}, k\end{array}$ & $0.75 \times 0.41 \mathrm{yr}^{-1}$ \\
\hline Age at recruitment & $a_{r}$ & O'Grady and Delanty (2001) & 2 years \\
\hline $\begin{array}{l}\text { Density-independent } \\
\text { SR term }\end{array}$ & $a$ & Poole et al. (2007) & $\begin{array}{l}0.0239 \\
\text { recruits/egg }\end{array}$ \\
\hline $\begin{array}{l}\text { Density-dependent SR } \\
\text { term }\end{array}$ & $b$ & Poole et al. (2007) & $4.07 \times 10^{-5}$ \\
\hline $\begin{array}{l}\text { Donor system spawn- } \\
\text { ing habitat area }\end{array}$ & $A_{\text {don }}$ & $\begin{array}{l}\text { ArcGIS, McGinnity et al. } \\
(2012)\end{array}$ & 12.5 ha \\
\hline $\begin{array}{l}\text { Recipient } \quad \text { system } \\
\text { spawning habitat area }\end{array}$ & $A_{\text {rec }}$ & $\begin{array}{l}\text { ArcGIS, McGinnity et al. } \\
(2012)\end{array}$ & 21.6 ha \\
\hline
\end{tabular}

Table 1: Model parameters for brown trout. 


\begin{tabular}{|c|c|c|c|}
\hline Description & Notation & Source of data & $\begin{array}{l}\text { Point esti- } \\
\text { mate(s) }\end{array}$ \\
\hline LVB length-at-infinity & $L_{\infty}$ & McLoone et al. (2019) & $105 \mathrm{~cm}$ \\
\hline LVB growth constant & $k$ & McLoone et al. (2019) & $0.22 \mathrm{yr}^{-1}$ \\
\hline $\begin{array}{l}\text { Length-body-mass re- } \\
\text { gression }\end{array}$ & $(\alpha, \beta)$ & $\begin{array}{l}\text { McLoone et al. 2019, } \\
\text { Lough Conn }\end{array}$ & $\begin{array}{l}(\exp (-5.49) \\
3.15)\end{array}$ \\
\hline $\begin{array}{l}\text { Residual natural mor- } \\
\text { tality }\end{array}$ & $D$ & Then et al. 2015 & $0.29 \mathrm{yr}^{-1}$ \\
\hline Age at recruitment & $a_{r}$ & Langangen et al. (2011) & 3 years \\
\hline $\begin{array}{l}\text { Density-independent } \\
\text { SR term }\end{array}$ & $a$ & Langangen et al. (2011) & $\begin{array}{l}0.495 \\
\text { recruits/adult }\end{array}$ \\
\hline $\begin{array}{l}\text { Density-dependent SR } \\
\text { term }\end{array}$ & $b$ & Langangen et al. (2011) & 0.0107 \\
\hline $\begin{array}{l}\text { Donor system spawn- } \\
\text { ing habitat area }\end{array}$ & $A_{\text {don }}$ & $\frac{\text { Mortimer and Worthington }}{(1942)}$ & 202 ha \\
\hline $\begin{array}{l}\text { Recipient system po- } \\
\text { tential (usable) spawn- } \\
\text { ing habitat area }\end{array}$ & $A_{\text {rec }}$ & ArcGIS & 1331(200) ha \\
\hline $\begin{array}{l}\text { Optimal predator-prey } \\
\text { length ratio }\end{array}$ & $\beta_{L}$ & $\begin{array}{l}\text { McLoone et al. (2019), Sec- } \\
\text { tion } 2.3 .2\end{array}$ & 5.69 \\
\hline $\begin{array}{l}\text { Tolerance for variabil- } \\
\text { ity in predator-prey } \\
\text { length ratio }\end{array}$ & $\sigma_{L}$ & $\begin{array}{l}\text { McLoone et al. 2019), Sec- } \\
\text { tion } 2.3 .2\end{array}$ & 0.564 \\
\hline $\begin{array}{l}\text { Optimal predator-prey } \\
\text { size ratio }\end{array}$ & $\beta_{W}$ & Estimate & 100 \\
\hline $\begin{array}{l}\text { Alternative prey } \\
\text { biomass size spectrum } \\
\text { exponent }\end{array}$ & $\lambda$ & Kelly et al. (2017) & 2.29 \\
\hline $\begin{array}{l}\text { Alternative prey } \\
\text { biomass size } \\
\text { 'richness' }\end{array}$ & $\kappa_{c}$ & \begin{tabular}{|l|} 
Kelly et al. $(2017) ;$ Fitzger- \\
ald et al. $(2018)$
\end{tabular} & $1.12 \times 10^{8}$ \\
\hline
\end{tabular}

Table 2: Model parameters related to northern pike population and pike predation. 
Trout

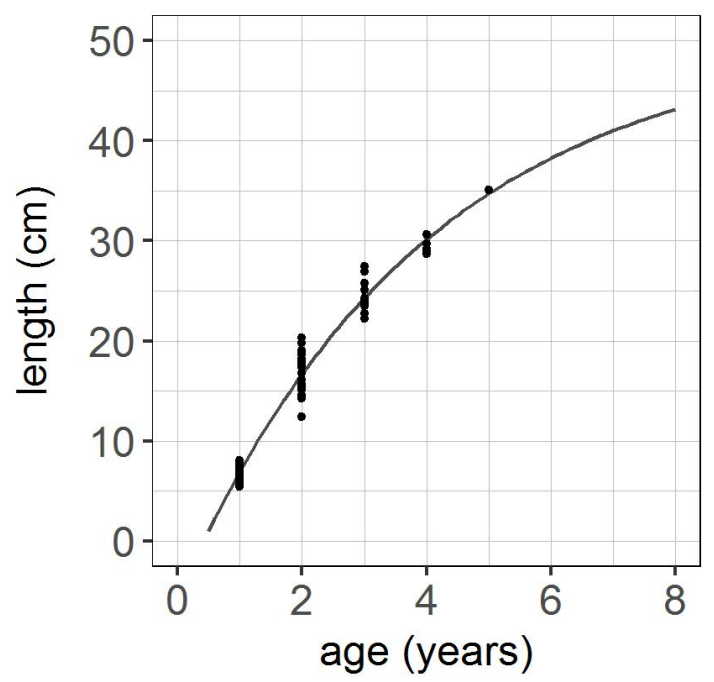

Pike

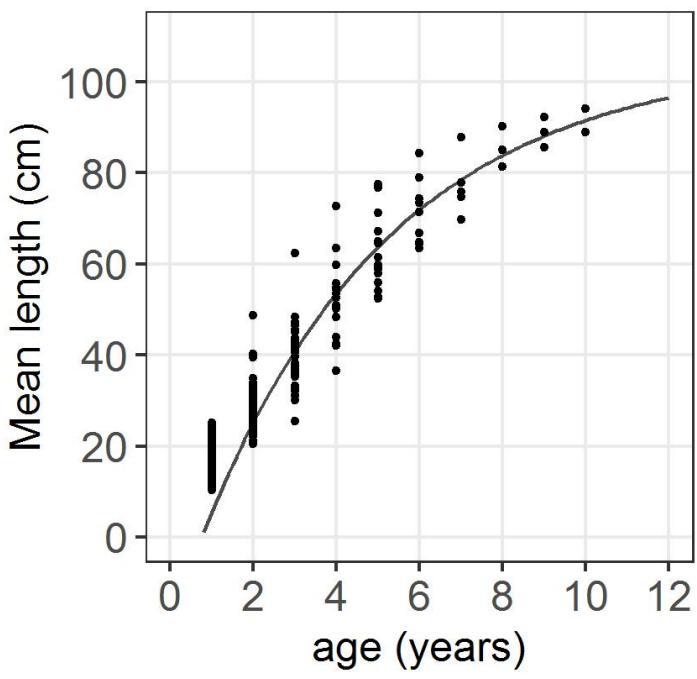

Figure 2: Back-calculated length-at-age data (points) and LVB growth curve regression based on mean length-at-age data for trout and pike.

\subsubsection{Estimating species-specific parameters}

Elements of the growth transition matrix $\boldsymbol{P}$ in population dynamics Equation (1) are calculated using the stochastic LVB model as represented through Equations A.2 and A.4. Estimates of LVB growth parameters $L_{\infty}$ and $k$ were determined from backcalculated length-at-age data derived from trout and pike fish scale samples. Scale samples were collected from trout caught in the IFI fish stock survey conducted on Lough Conn in 2016 (Kelly et al. 2017) and from a sub-sample of all pike caught during the dietary study on the same lake from August 2016 to July 2017 (McLoone et al., 2019). The deterministic LVB growth model was fitted to these mean length-at-age data using nonlinear regression as shown in Figure 2, Length-body-mass relationship parameters were also estimated from these datasets using linear regression. Growth and length-body-mass regression parameters are tabulated in Tables 1 and 2.

Predator and prey population length structures were defined based on a balance of model realism and availability of data, as advocated by (Punt et al., 2013). In the absence of catch-at-length data, and recognising the relatively simple model representation of predation, we discretised each of the two target populations into five classes of equal length. This contrasts with single-species size-structured stock assessments which typically feature $>20$ individual size-classes (Punt et al. 2013$)$. The initial length class 
interval was chosen with reference to growth data (Figure 2) and age-at-recruitment information. For example, studies indicate that most brown trout migrate downstream from natal rivers into Lough Conn around age two (O'Grady and Delanty, 2001), and back-calculated lengths for the sample trout of this age in Lough Conn (Figure 2) were observed to lie between $12 \mathrm{~cm}$ and $20 \mathrm{~cm}$. A minimum length of $16 \mathrm{~cm}$ was selected because most back-calculated lengths were greater than this minimum. A maximum length of $56 \mathrm{~cm}$ was selected to incorporate individual variation around the $L_{\infty}$ value of $50.5 \mathrm{~cm}$. A sequence of five length class intervals of width $8 \mathrm{~cm}$ spanned this range (see Table 3). Similarly, pike recruits were considered to be of age 3 (Langangen et al., 2011) and based on growth data shown in Figure 2 the lower boundary for the smallest length class was selected to be $30 \mathrm{~cm}$ and the upper boundary of the largest length class was selected to be $105 \mathrm{~cm}$ (corresponding to the $L_{\infty}$ estimate as listed in Table 2). The pike population is structured into five length intervals of $15 \mathrm{~cm}$ width within this range (see Table 4).

Long-term monitoring programmes and datasets for lake-migratory brown trout and northern pike juveniles and adult spawning populations in large Irish lakes have not been reported in scientific literature (or grey literature). Instead, a proxy stock-recruitment study was identified from scientific literature for each species, an appropriate stockrecruitment model was fitted to the empirical data, and the fitted stock-recruitment relationship was extrapolated from the monitored 'donor' population to the unmonitored 'recipient' Lough Conn population.

The stock-recruitment model for brown trout was extrapolated from a sea-migratory trout population in the Burrishoole system in the west of Ireland (Poole et al., 2007). This extensively monitored population was considered to most closely resemble the migratory behaviour (to and from large water-bodies) and spawning environment (a large network of small streams) of brown trout in large freshwater lakes. Poole et al. (2007) found that the purely compensatory Beverton-Holt SR model (Beverton and Holt, 1957) best described the stock-recruitment dynamics of this sea trout population - consistent with other migratory salmonids at the scale of whole river networks (Milner et al., 2003). A Bayesian approach was used to estimate the Beverton-Holt SR parameters and thus yielded probability distributions for each stock-recruitment parameter (see Figure A.1 in Appendix A.

Pike recruitment was derived from population monitoring data collected by the Freshwater Biological Association of the UK (https://www.fba.org.uk) at Windermere. In particular, a stock-recruitment relationship was inferred from synthetic age-structured abundance estimates from an age-structured stock assessment analysis (Langangen et al. 


\begin{tabular}{llllllll}
\hline $\begin{array}{l}\text { Length class } \\
\text { interval }(\mathrm{cm})\end{array}$ & $\begin{array}{l}\text { Sex } \\
\text { ratio }\end{array}$ & $\begin{array}{l}\text { Maturity } \\
\text { proportion }\end{array}$ & $\begin{array}{l}\text { Fecundity } \\
(\text { female })\end{array}$ & $\begin{array}{l}\text { Mean } \\
\text { per } \\
\left(f_{l}\right)\end{array}$ & $\begin{array}{l}\text { eggs } \\
\text { adult }\end{array}$ & $\begin{array}{l}\text { Proportion } \\
\text { of recruits } \\
\left(p_{l}\right)\end{array}$ & $\begin{array}{l}\text { Angling } \\
\text { vulnerabil- } \\
\text { ity }\end{array}$ \\
\hline$(16,24)$ & 0.55 & 0.0 & 0 & $\approx 0$ & 0.95 & 0.0 \\
$(24,32)$ & 0.55 & 0.5 & 250 & $\approx 14$ & 0.05 & 0.25 \\
$(32,40)$ & 0.625 & 1.0 & 1027 & $\approx 642$ & 0.0 & 1.0 \\
$(40,48)$ & 0.5 & 1.0 & 1600 & 800 & 0.0 & 1.0 \\
$(48,56)$ & 0.5 & 1.0 & 1600 & 800 & 0.0 & 1.0 \\
\hline
\end{tabular}

Table 3: Length class intervals and length-specific reproductive parameters estimated from Poole et al. (2007) for trout.

2011). Langangen et al.'s analysis of this synthetic data - wherein age 3 pike were classified as recruits $\left(a_{r}=3\right)$ and age 3-9 pike as adult stock — did not assume a particular functional form. However, we assumed the SR relationship had Ricker form (Ricker, 1954) in order to represent the cannibalistic tendencies of pike (see Raat, 1988, Grimm, 1981, for example) which manifest as overcompensation in recruitment. Details of the Bayesian approach to parameter estimation for the Ricker model are provided in Appendix A and Figure A.1 shows the inferred posterior distributions.

The most probable values for the trout and pike SR parameters obtained from the Bayesian analyses are presented in Tables 1 and 2. Adult spawning stock is measured in terms of egg deposition for trout and total adult abundance for pike. In the absence of reproductive parameter estimates for Lough Conn trout, the age-specific sea trout parameters used by Poole et al. (2007) were converted to length-specific brown trout parameters as shown in Table 3. Trout spawning stock was calculated from lengthstructured abundances and mean-eggs-per-adult from Table 3 using Equation (5). Pike spawning stock was calculated by summing abundances over all length classes.

It was necessary to extrapolate the stock-recruitment models from the monitored donor populations (Burrishoole, Windermere) to the recipient case study populations (Lough Conn). For the purposes of direct extrapolation it was expedient to express spawning stock and juvenile recruitment in terms of densities (relative to the spawning habitat areas in each system) rather than abundances. The estimation of the donor population SR parameters and the process of extrapolating an SR relationship from a donor to a recipient population are described in Appendix Sections A.3 and A.2, respectively. In the formulation described in Section A.2, direct extrapolation of a SR relationship 


\begin{tabular}{llll}
\hline $\begin{array}{l}\text { Length class } \\
\text { interval }(\mathrm{cm})\end{array}$ & $\begin{array}{l}\text { Annual specific } \\
\text { food consumption } \\
\text { (g per g) }\end{array}$ & $\begin{array}{l}\text { Proportion } \\
\text { of recruits } \\
\left(p_{l}\right)\end{array}$ & $\begin{array}{l}\text { Removals } \\
\text { vulnerabil- } \\
\text { ity }\end{array}$ \\
\hline$(30,45)$ & 6.0 & 0.95 & 0.1 \\
$(45,60)$ & 4.0 & 0.05 & 0.5 \\
$(60,75)$ & 3.0 & 0.0 & 1.0 \\
$(75,90)$ & 2.0 & 0.0 & 0.9 \\
$(90,105)$ & 2.0 & 0.0 & 0.1 \\
\hline
\end{tabular}

Table 4: Length class intervals and associated length-specific predation parameters estimated from Heikinheimo and Korhonen (1996), recruitment proportions, and management removals selectivity for pike.

relies on an estimate of the ratio of the spawning habitat areas for the recipient and donor populations in addition to donor SR parameters. We attempt to encapsulate the uncertainty in characterising recruitment using particular measures of spawning habitat area (e.g. wetted fluvial accessible area of natal streams for trout) and the uncertainty in transporting SR relationships between populations in different lakes by defining a range of plausible habitat area ratio values through probability distributions. The proposed probability distributions representing estimated ratios of recipient-to-donor habitat areas for the trout and pike populations are shown in Figure 3. Details of how these (lognormal) distributions were specified are provided in Appendix Section A.4.

Background natural mortality for pike was assumed to be constant and the growthbased estimator Equation (3) applied to LVB parameter values (Table 2 produced an estimate of $0.29 \mathrm{yr}^{-1}$ similar to mortality estimates obtained from the Windermere stock assessment (Langangen et al., 2011). Residual natural mortality for trout was calculated by discounting the growth-based mortality estimate in order to exclude possible predation contributions, i.e. an initial estimate of $0.41 \mathrm{yr}^{-1}$ derived from Equation (3) was reduced by $25 \%$ to $0.31 \mathrm{yr}^{-1}$.

\subsubsection{Estimating parameters for multi-species interactions}

Predation mortality as defined in Equation (10) includes multi-species interaction parameters such as length-specific annual specific food rations for the predator species and several parameters related to dietary composition. Heikinheimo and Korhonen (1996) estimated annual specific food consumption of $7-5$ grams per one gram of pike $\left(\mathrm{g} \mathrm{g}^{-1}\right)$ 


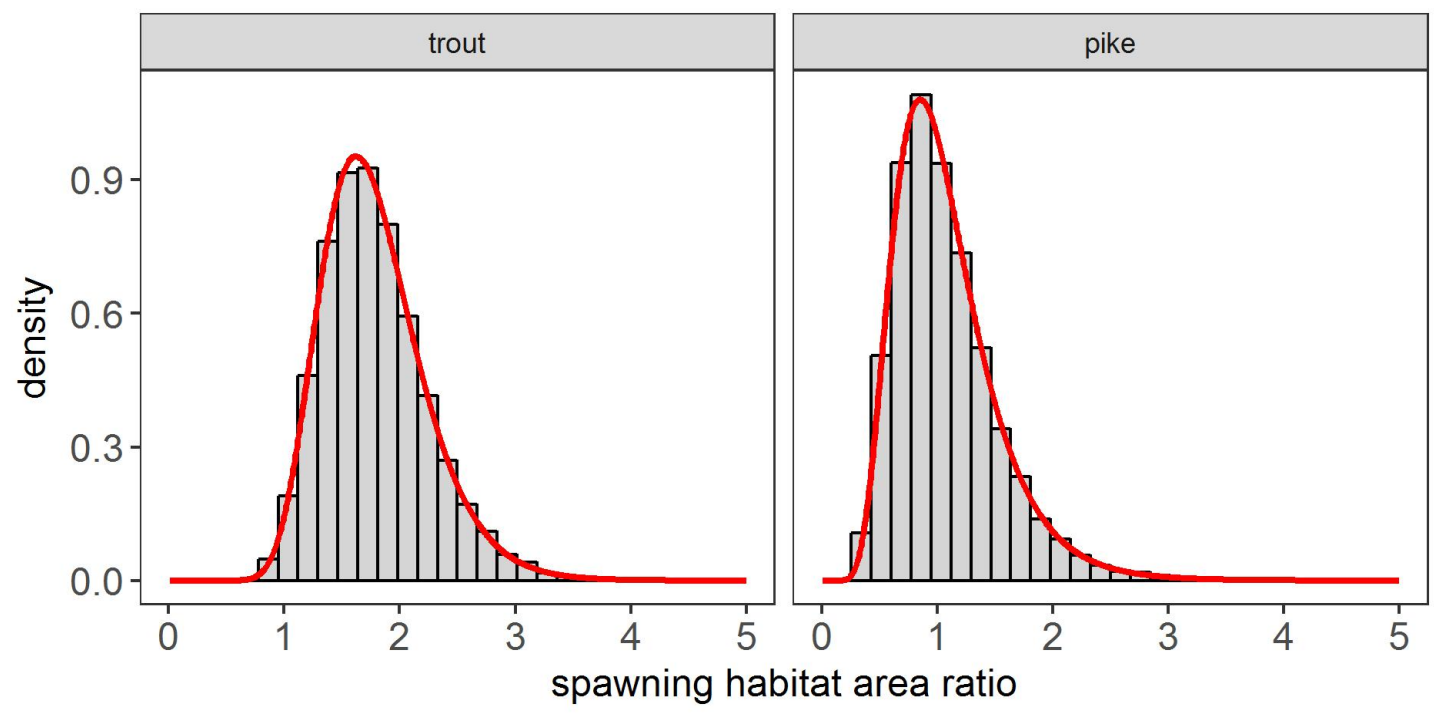

Figure 3: Proposed probability density function representation of recipient-to-donor population spawning habitat area ratio for pike and trout.

and 4-3 $\mathrm{g} \mathrm{g}^{-1}$ for two age-groups (1-2 years old and 3-6 years old respectively) of pike populations in two lakes in north-eastern Finland. These age group estimates were distributed among the length classes as shown in Table 4.

The dietary composition fraction defined in Equation (14) is determined by the biomass-at-length of the predator and prey populations (dynamic), the potential biomass of alternative prey (constant), and the fraction of each prey type available to the predator. Calculation of the available fraction $(12)$ of potential prey requires the specification of predator-prey habitat overlap, species vulnerability and predator size-preference (13). Habitat segregation was expected to be relatively unimportant for the Lough Conn fish community so that habitat overlap $\sigma_{i}$ with the predator population was assumed to be equal for all prey species. Species vulnerabilities $q_{i}$ were prescribed in three distinct combinations, corresponding to implicit stakeholder beliefs, as part of the treatment of ecological uncertainty as described in Section 2.4.2.

Length preference parameters were estimated from pooled stomach contents data recorded during the dietary study for pike on Loughs Conn and Derravaragh (McLoone et al., 2019). Insufficient numbers of large pike were sampled in the Lough Conn study and so Lough Derravaragh data were also included. An overview of the pike length and prey item length data is shown in Figure 4. Note that cannibalism of adult pike (i.e., pike greater than $30 \mathrm{~cm}$ ) is evident in the Derravaragh data but not in the Conn 
data. Prey lengths were estimated based on the prey remains found in the stomach and morphometrics were used to estimate length where only partial skeletal remains were found (McLoone et al. 2019). A histogram of pike-prey length ratios is shown in Figure 4. Each prey item was treated as an independent sample and, although prey type is distinguished by species in Figure 4, prey species preference was ignored when fitting Equation (13) to the data. A nonlinear regression applied to the length-ratio data yielded an estimate of $\beta_{L}=5.7$ for the optimal length ratio and $\sigma_{L}=0.56$ for the length ratio tolerance. These preliminary estimates require further examination because, as noted by Floeter and Temming (2003), Figure 4 presents the length composition of prey in the diet of pike which is a combination of the predator size preference and the length composition of prey in the surrounding environment.

The size spectrum representation (7) of alternative prey biomass in the ambient environment of pike in Lough Conn required estimates of an exponent parameter $\lambda$ and an ecosystem richness parameter $\kappa_{c}$. The size-spectrum exponent or slope determines how potential prey biomass is distributed by organism size: larger exponents indicate a greater abundance of small prey fish and organisms and fewer large fish. An estimate of the biomass size spectrum slope was obtained from Lough Conn empirical fish stock survey data (Kelly et al., 2017) following the approach described by Sweeting et al. (2009) and Emmrich et al. (2011) and detailed in Appendix Section A.5.

Estimation of the ecosystem richness parameter $\kappa_{c}$ is more difficult because it requires an absolute biomass estimate for at least one logarithmic size class or component of the ecosystem. We devised an approximate scaling method in order to raise the survey biomass distribution up to an absolute biomass distribution (see Appendix A.5 for full details). A scale factor was calculated by comparing the surplus production estimate of total exploitable trout biomass for Lough Conn (Fitzgerald et al., 2018), time-averaged over the period 1975-2001, to the biomass of exploitable trout sampled in the Lough Conn fish stock survey (Kelly et al., 2017). This information combined with empirical fish stock survey biomass data yielded a point estimate for ecosystem richness of $\kappa_{c}^{0}=$ $1.12 \times 10^{5} \mathrm{~kg}$, although uncertainty in this estimate is very large.

\subsection{Model behaviour}

Using the case study, it is possible to examine the model's behaviour in detail; this is an essential step towards convincing stakeholders that it realistically captures the essential features of influence on their suggested management actions. 

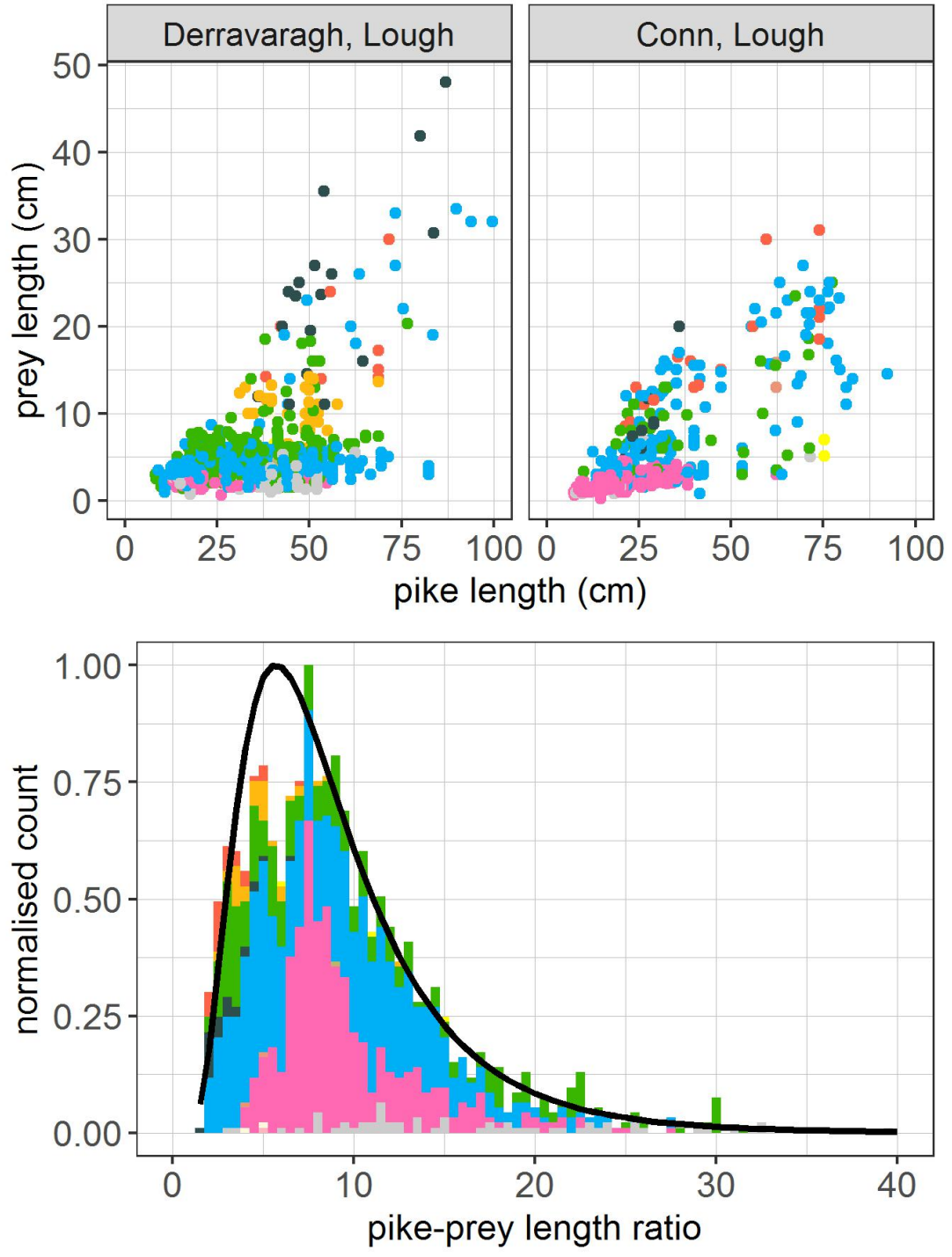

Species

Brown trout

Common newt

Lamprey sp.

Perch

Pike

Roach

Roach $\mathrm{x}$ bream

Salmon

Stickleback (3sp)

Stone loach

Tench

Unidentified fish

Figure 4: Pike and prey fish length data from dietary study on Loughs Conn and Derravaragh in overview form (upper plots) and in a histogram representation (lower plot). 


\subsubsection{Sensitivity analysis}

A sensitivity analysis, in the form of a graphical exploration of model response to variations in certain model parameters, was conducted to understand potential model behaviours. Model behaviour is summarised through a single model output metric. Our choice of metric reflects the fishery management objectives, i.e., to enhance trout abundance and hence the trout angling experience. We selected the exploitable trout biomass (aggregate trout biomass for all length classes above a minimum length limit of $30 \mathrm{~cm}$ ) at steady state $\tilde{B}$ as the performance measure for the assessment of alternative management actions and investigated the sensitivity of this measure to parameter perturbations. This quantity is derived from the length-structured abundance for trout $N_{l, t}^{(2)}$ as follows

$$
\tilde{B}=\sum_{l=1}^{J_{2}} N_{l, T_{\infty}}^{(2)} w_{l}^{(2)} s_{l}^{(2)},
$$

where $w_{l}^{(2)}$ is the body-mass of a trout at the mid-point length of class $l$ and $T_{\infty}$ is the projection window, by the end of which effective steady state is considered to have been reached. The response of exploitable biomass to variations in alternative prey resource parameters, which define the ecosystem context for the population interactions; in the predator's predation parameters, which define the population interactions; and in both focal species' stock-recruitment parameters and the focal prey species' residual natural mortality, which characterise these species' population dynamics, were examined in the zero-exploitation management scenario.

\subsubsection{Uncertainty analysis}

Uncertainty is explicitly accounted for in a quantitative evaluation of management action performance by admitting operating model uncertainty. Reliable quantification of uncertainty in fisheries stock assessments is important where policy and management actions depend on assessment outputs. A broad suite of methods for measuring uncertainty are available and this diversity of approaches has motivated several cross-comparison studies (Patterson et al., 2001; Magnusson et al., 2013). The Bayesian approach to uncertainty analysis is independent of the population dynamics model (Punt and Hilborn, 1997), but it does rely on comprehensive data for the stock under assessment for the construction of a likelihood function. In the absence of such observational data, we assessed uncertainty in model outcomes using an informal Bayesian treatment by applying Monte Carlo analysis involving 'prior' distributions of certain parameters across an array 
of potential ecosystem scenarios.

The intuitive uncertainty analysis adopted involved first identifying the most influential model input parameters through a sensitivity analysis. If the model was relatively insensitive to changes in a given parameter then a point estimate for that parameter was used. More influential parameters were treated in two ways depending on the data available for parameter estimation. Those parameters based on extensive data were estimated using Bayesian inference. Where estimation of the parameter and its associated confidence intervals was difficult or confidence intervals were very wide, the parameter was allowed to take several different values representing quite different regimes of behaviour. Langsdale (2008) suggested such a scenario-based approach to tackling system uncertainty. This approach allows us to examine plausible alternative scenarios representing possible future conditions in a clear manner. The scenario approach was adopted for the relative prey species vulnerabilities $\left(q_{1}, q_{2}\right)$ and for the ecosystem richness parameter $\kappa_{c}$ to give three model 'configurations' and three ecosystem scenarios.

Three model configurations were considered corresponding to different combinations of prey species vulnerabilities $\left(q_{1}, q_{2}\right)$ that express broad generalisations about the beliefs of different stakeholders concerning the likely predator-prey interactions between pike, trout and other prey species. One model configuration $\left(q_{1}, q_{2}\right)=(1,1)$ represented the 'pike angler belief' that all species, including pike, are equally vulnerable to pike predation. A second configuration $\left(q_{1}, q_{2}\right)=(0,2)$ represented the 'trout angler belief' that trout are more vulnerable to pike predation than other prey and adult cannibalism is unimportant in regulating pike abundance. A third, intermediate configuration $\left(q_{1}, q_{2}\right)=$ $(0,1)$ represented a 'neutral belief' wherein trout and other prey are equally vulnerable to pike and adult cannibalism is absent in pike. These model configurations are gross simplifications and generalisations of more nuanced and varied stakeholder positions but are useful for treating ecological uncertainty.

Uncertainty in the ecosystem richness parameter $\kappa_{c}$ estimate is very large (see Appendix A.5 and so we envisaged three different ecosystem scenarios: a medium level of alternative prey abundance represented by the 'best' estimate $\kappa_{c}^{0}$, a scarcity of alternative prey represented by $\kappa_{c}^{0} / 3$ and plentiful alternative prey represented by $3 \kappa_{c}^{0}$. Each ecosystem scenario may be considered an equally plausible future state representing low, medium or high levels of alternative prey as a proxy for eutrophication. A post hoc comparison of relative proportions of target and alternative prey species biomasses from model projections and empirical fish stock survey data may be used to identify which scenario most closely resembles the current lake ecosystem state.

The remaining influential parameters, from the stock-recruitment relationships for 
both focal species and non-predation natural mortality for the focal prey species, were expressed in probability distribution form through Bayesian inference of existing data (density-dependent and density-independent SR parameters) or expert judgement (spawning habitat area ratio and natural mortality parameters). Species-specific SR parameter values were found to be correlated and so the density-independent parameter was generated from the inferred 'prior' distribution from which the density-dependent parameter was derived using a linear correlation with random noise (see Appendix A.3).

Therefore, uncertainty in influential model parameters was treated through a combination of Monte Carlo analysis and a scenario-based approach by simulating outcomes for each randomly realised set of empirically estimable parameters across each ecosystem scenario and model configuration. Model outcomes were measured through steady-state exploitable trout biomass as defined in Equation (15). The multi-species system was observed to reach approximate steady state, where further advances in time yield negligible changes in the populations, after $T_{\infty}=50$ model years. Distributions of outcomes were constructed from 20,000 model realisations in each ecosystem scenario and model configuration.

\subsection{Management strategy evaluations}

The model reported here provides a platform for testing candidate fisheries management actions proposed by stakeholders. Although stakeholder suggestions were not formally collated, pike removals and the regulation of trout angling pressure were the management tools most frequently suggested for enhancing brown trout abundance. Therefore, a particular management scenario or action is represented through a combination of trout removal and pike removal mortality rates. Our model allows the likely outcomes of such actions to be assessed in an informal management scenario framework based on constant removal rate projections incorporating uncertainty in several influential model parameters. Furthermore, the dynamics of discrete model configurations representing commonly held opposing stakeholder beliefs about trout-pike behaviour were compared in seeking to include stakeholder perceptions and thus engage stakeholders in the fisheries management process.

Two key components of model parameter uncertainty were addressed in the assessment of management actions for each model configuration. Three different 'ecosystem richness' scenarios, characterised by availability of alternative prey ('scarce', 'moderate', 'plentiful'), were introduced in order to present the breadth of possible system responses to each management action in an intuitive and accessible manner. Within each ecosys- 
tem scenario, management actions were represented as fixed inputs to the model and distributions of outcomes were obtained using Monte Carlo methods in order to account for uncertainty in stock-recruitment parameters (the second key uncertainty component after ecosystem richness) and the non-predation natural mortality for the prey. Thus, the consequences of the management actions are assessed for three different ecosystem scenarios, while expressing uncertainty in stock-recruitment dynamics, for each model configuration.

Ensembles of model outcomes, expressed through the exploitable biomass for trout at steady population state, were computed for three levels of trout removals, combined with three levels of pike removals across each of the three alternative prey resource scenarios. Trout and pike removal mortalities (representing management actions) were assumed to be constant within simulations. This process yielded a total of 27 different model projection ensembles, where input ranges for each management level fall within realistic ranges, for each model configuration.

\section{Results}

\subsection{Model sensitivity}

The response of the steady-state exploitable trout biomass to perturbations in the biomass size spectrum exponent and richness, optimal pike-prey length and body-mass ratios, annual specific pike ration and trout residual natural mortality for all three model configurations is shown in Figure 5. Model sensitivity was computed over a range of parameter values, corresponding to realistic parameter uncertainty where possible. For example, estimates of the annual specific food consumption by Heikinheimo and Korhonen (1996) were considered to be robust and so model response was calculated for variations of $\pm 50 \%$ about the best estimate. On the other hand, it has been acknowledged that the ecosystem richness parameter $\kappa_{c}$ estimate is very uncertain and the model response to values between one tenth of and four times the best estimate was examined. A standardised or normalised ecosystem richness parameter, defined as $\hat{\kappa}_{c}=\kappa_{c} / \kappa_{c}^{0}$ where $\kappa_{c}^{0}$ is the best estimate, has been introduced for ease of presentation.

Figure 5 shows that the greatest variation in exploitable trout biomass occurs over the range of plausible $\kappa_{c}$ values, irrespective of model configuration. Model sensitivity increases (and trout biomass declines most rapidly) as the absolute biomass of alternative prey represented by $\kappa_{c}$ decreases. This observation is consistent with empirical studies of pike-trout coexistence patterns, where the presence of alternative prey species was found 

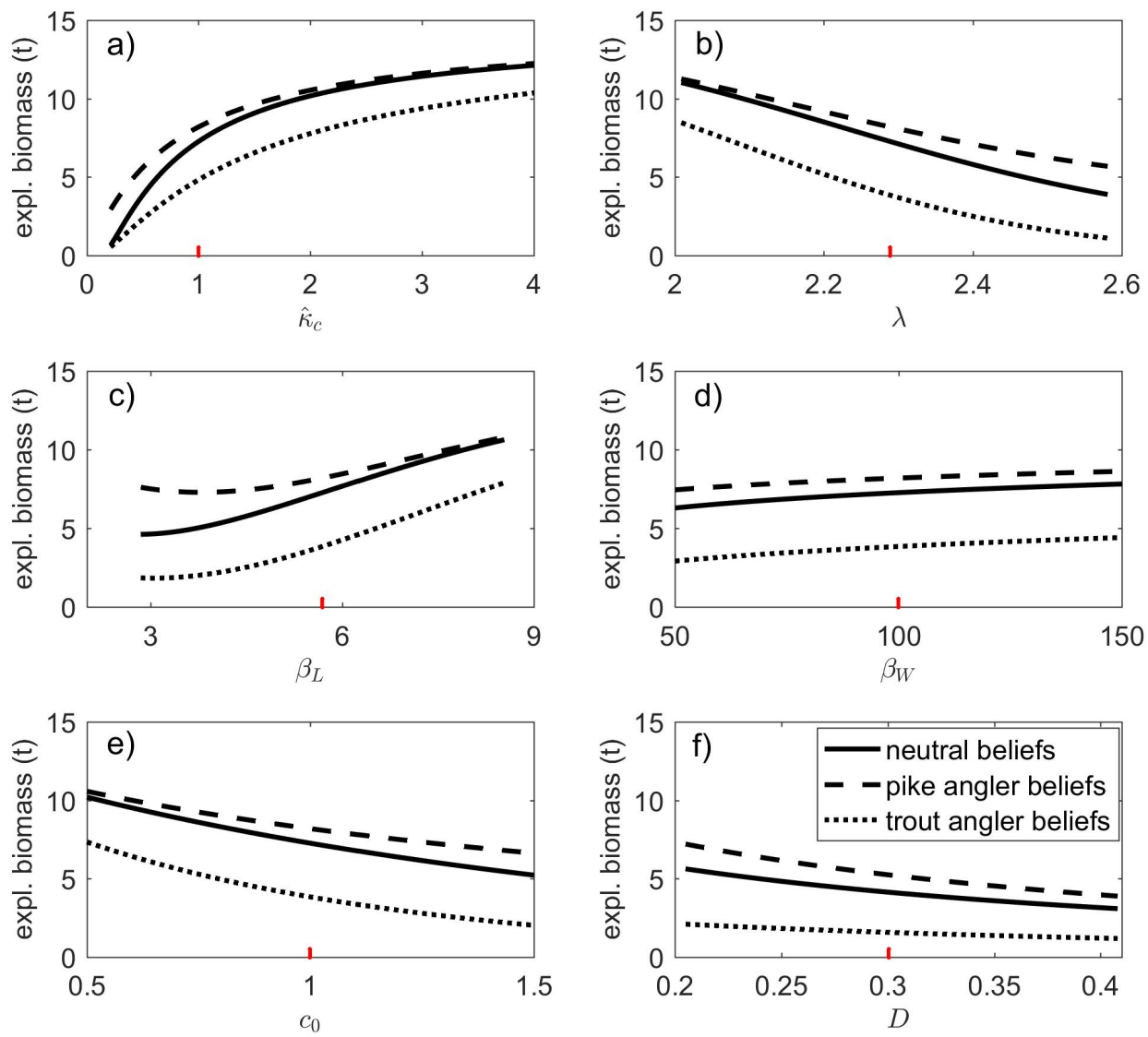

Figure 5: Exploitable brown trout biomass response to changes in (a) standardised alternative prey resource spectrum 'richness' $\hat{\kappa}_{C}$, (b) resource spectrum slope $\lambda$, (c) optimal pike-trout length ratio $\beta_{L}$ and (d) optimal pike-prey body-mass ratio $\beta_{W}$, (e) annual pike food consumption scale factor $c_{0}$, and (f) trout residual natural mortality $D$. Model configurations considered include the no cannibalism case and equal prey vulnerability (solid line), cannibalism and equal prey vulnerability (dashed line) and increased trout vulnerability but no cannibalism (dotted line). Red lines on parameter axes denote point estimates. 
to support coexistence (Hein et al. 2014) (although lake size was a more significant predictor of coexistence). Acute reductions in trout biomass after pike introductions in small lakes lacking abundant alternative prey have been observed (Sepulveda et al. 2013: Hesthagen et al. 2015) and such interactions are represented by the small $\hat{\kappa}_{c}$ model regime. It is also noteworthy that the model was more sensitive to changes in the optimal predator-prey length ratio $\beta_{L}$ than in the optimal predator-prey size ratio $\beta_{W}$, where the former is the primary determinant of the suitable fraction of length-structured species biomass and the latter the primary determinant of the suitable fraction of alternative prey.

The inclusion of intraspecific predator mortality (cannibalism) in the predation model mitigates the negative impacts of pike on trout population across all parameter variations. Figure 5 a shows that reductions in alternative prey biomass have a less negative impact on brown trout stocks when the model includes an adult pike cannibalism mechanism. Cannibalism within the pike population mitigates the impact of pike predation on the trout population because some predation pressure is shifted from trout to pike of a similar size. This effect is most noticeable in the small alternative prey biomass regime. The reductions in trout biomass with decreasing optimal pike-prey length ratio observed in Figure 5 c arise because fewer trout can attain size refuge from pike predation for pike populations that select relatively larger prey. However, the model including predator cannibalism also projects a somewhat counter-intuitive increase in trout biomass for optimal predator-prey length ratio below three, probably caused by a rapid increase in available pike biomass as pike select relatively larger prey. The biomass projections from the model configuration incorporating no pike cannibalism and increased trout vulnerability $\left(q_{1}=0, q_{2}=2\right)$ are substantially smaller than for the no cannibalism, equal trout vulnerability case $\left(q_{1}=0, q_{2}=1\right)$ but model trends are very similar in both cases.

A careful examination of how different levels of ambient prey abundance affect the species interactions was necessary because of the influential nature of the total ambient prey abundance parameter and the significant uncertainty in that parameter. This examination was achieved by exploring model sensitivity to variations in other likely influential parameters for three different $\kappa_{c}$ values $\left(\kappa_{c}^{0} / 3, \kappa_{c}^{0}\right.$ and $\left.3 \kappa_{c}^{0}\right)$ corresponding to the plentiful, moderate and scarce alternative prey biomass resource scenarios, respectively. Stock-recruitment dynamics have a strong influence on long-term population trajectories and so model projections are likely to be sensitive to focal predator and prey species stock-recruitment parameters. Therefore, a sensitivity analysis of prey species and predator species SR parameters across three levels of alternative prey biomass was conducted in order to understand how the projected population dynamics change along 

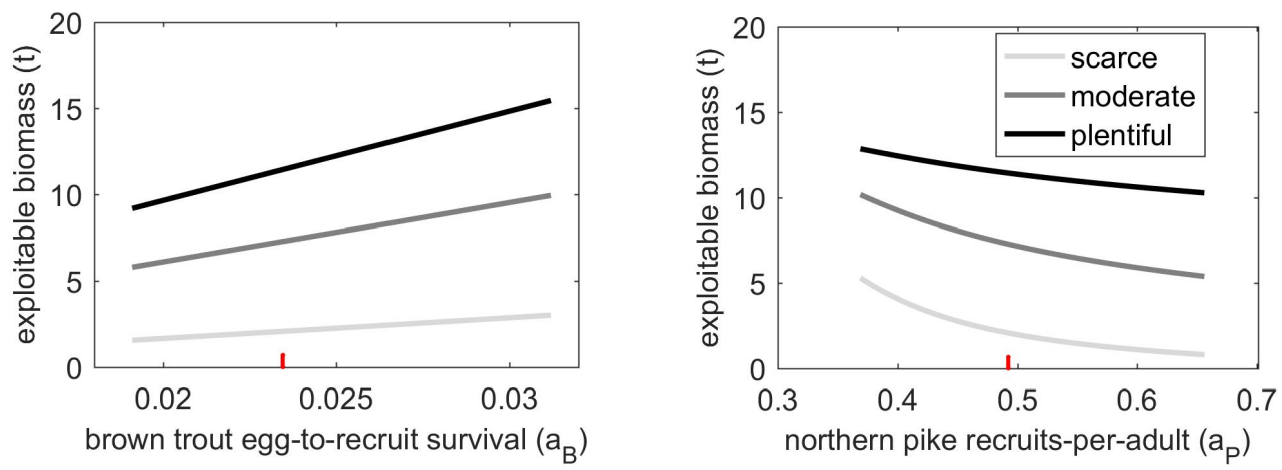

Figure 6: Variation in exploitable brown trout biomass with (a) brown trout egg-torecruit survival $\left(a_{B}\right)$ at low population density and (b) pike recruits-per-adult $\left(a_{P}\right)$ at low population density for three different alternative prey biomass scenarios. Red lines on parameter axes denote point estimates.

a gradient of ecosystem prey abundances. For simplicity of exposition, sensitivity across ecosystem scenarios was considered only for the model configuration featuring no adult cannibalism and equal trout and alternative prey vulnerability.

The exploitable trout biomass response to changes in the density-independent SR parameters for each species, i.e. trout egg-to-recruit survival at low densities $\alpha_{B}$ and pike recruits-per-adult at low densities, are shown in Figure6. In each case, the SR parameter was varied over the $99 \%$ confidence intervals obtained from the model fitting process based on empirical data (see Appendix A). Exploitable trout abundance increases as the trout egg-to-recruit survival rate improves and the rate of biomass increase is greatest when the biomass of alternative prey in the ecosystem is most plentiful (and interactions between small trout and pike are weakest). In contrast, the exploitable trout biomass is diminished as average pike recruits-per-adult increases. The reduction in trout biomass appears most acute when the biomass of alternative prey in the ecosystem is scarce. The influence of pike recruitment on trout biomass is dampened when the alternative prey resource is more plentiful.

\section{$3.2 \quad$ Uncertainty analysis}

The sensitivity analysis reported in Section 3.1 indicates that the model is most sensitive to the target species stock-recruitment parameters and the ecosystem richness or alternative prey species abundance parameter within the range of plausible values for those parameters. Model sensitivity to residual trout mortality is significant only in the model configuration representing pike beliefs; nevertheless, uncertainty in this param- 

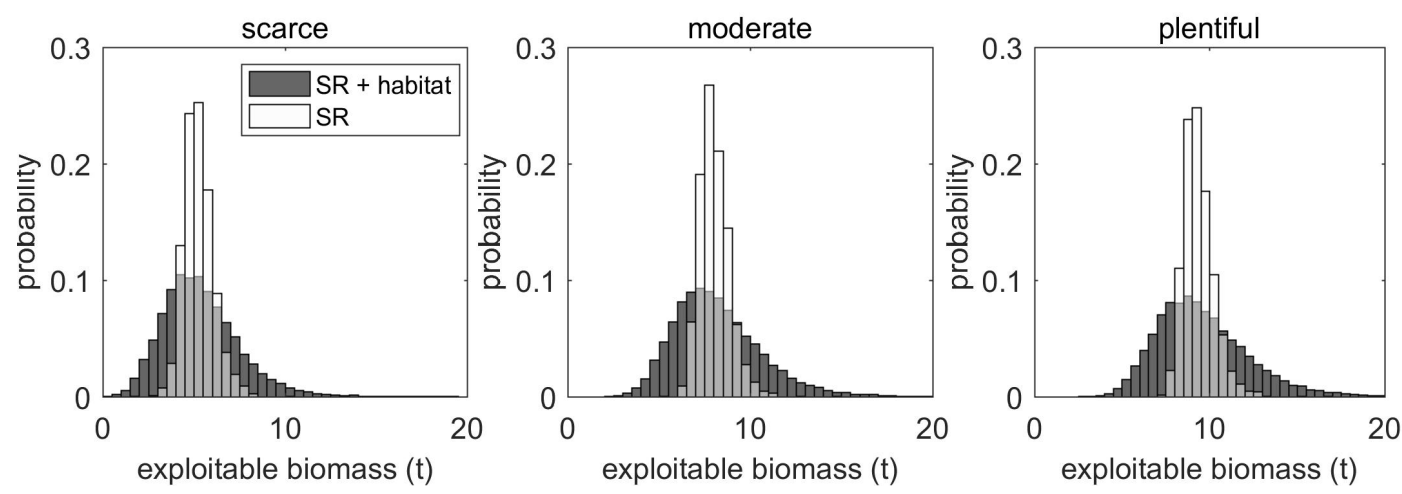

Figure 7: Distributions of exploitable brown trout biomass for each alternative prey biomass scenario for low angling (trout) and management (pike) removals.

eter was incorporated by assuming a uniform distribution for $D$ across $\left(0.5 D_{\text {est }}, D_{\text {est }}\right)$. Uncertainty in model outcomes is assumed to be dominated by this restricted set of parameters and so the effects of uncertainty in growth process and other pike predation process parameters on the performance of management actions are neglected.

Before evaluating the full array of management actions it is useful to examine how uncertainty propagates from stock-recruitment parameters through to model outcomes (exploitable stock biomass) by focusing on the outcomes of an individual management scenario. A baseline low angling and low management removals strategy was selected as an appropriate scenario. Using the neutral model configuration we first calculated a distribution of exploitable trout biomass including uncertainty in SR parameters for the focal species (see Figure A.1 in the Appendix) only. We then calculated a biomass distribution allowing for uncertainty in the spawning habitat area ratios (see Figure 3), as well as the SR parameters, for each focal species. These biomass distributions are compared in Figure 7 for each alternative prey abundance scenario. Much of the uncertainty arises from the SR extrapolation process, i.e. transportation of SR relationships from other species and systems to the target species in the case study lake. This is expected as the process of directly extrapolating from monitored to unmonitored populations based on variations in habitat area alone can significantly underestimate actual uncertainty (Prévost et al., 2003). We attempt to avoid such underestimation by defining prior habitat area ratio probability distributions (based on a mixture of judgement and available data) with realistically large ranges of potential values reflecting the actual uncertainty as described in Appendix A.4. 


\subsection{Using the model in the assessment of management actions}

Stakeholders indicated that pike removals and trout angling pressure were likely to be key factors in the successful management of trout populations in the designated Irish lakes. The distribution of management performance metric responses to different pike and trout exploitation pressures across three alternative prey abundance scenarios, for the model configuration representing an intermediate set of beliefs, i.e. no adult pike cannibalism and equal trout and other prey vulnerability, are illustrated in bar chart form in Figure 8. The range in possible outcomes primarily reflects uncertainty in pike and trout SR relationships and in their extrapolation from other populations.

Three categories of exploitation or fishing pressures - zero, low and high - were considered for each species. The highest recreational trout angling exploitation pressure was assigned a value of $0.3 \mathrm{yr}^{-1}$ which is similar to the fishing mortality value producing maximum sustainable yield $\left(F_{M S Y}\right)$ for many European marine stocks (Rindorf et al., 2017 ) and has been identified as a typical $F_{M S Y}$ for large marine species (Deriso, 1982 , Jacobsen et al., 2013). Fishing mortality corresponding to low angling pressure was prescribed a value of $0.15 \mathrm{yr}^{-1}$. These fishing mortality rates were also assigned to the low and high pike management removal categories. Each permutation of trout angling pressure and pike removals was considered in a management scenario matrix across the three alternative prey scenarios. The minimum length limit of $30 \mathrm{~cm}$ for trout on Lough Conn was represented through trout vulnerability coefficient values for each length class as shown in Table 3. Management removals of pike were achieved by electrofishing for smaller pike (represented by a vulnerability coefficient of $s_{l}=0.1$ for the smallest length class) and using gillnets for larger pike (targeting pike greater than $50 \mathrm{~cm}$ ). Removal of pike above $85 \mathrm{~cm}$ is prohibited, so selectivity for the largest class was set close to zero (allowing for incidental mortality in gillnet removals). Recreational pike fishery removals are expected to be small compared to management removals because catch and release is the dominant practice among pike anglers. Thus, the recreational pike fishery is not represented in the model.

Figure 8 shows that pike removals had the most positive effect on trout biomass when alternative prey was scarce across all levels of trout fishing pressure. Median exploitable trout biomass (i.e. biomass of trout greater than $30 \mathrm{~cm}$ in length) increased by a factor of 2.4 and 3.7 by imposing low and high levels of pike removals, respectively, in the scarce alternative prey scenario in the absence of trout fishing (see the top row of Figure 8). Median exploitable trout biomass increased by a factor of only 1.12 and 1.18 after introducing low and high pike removals, respectively, when alternative prey 


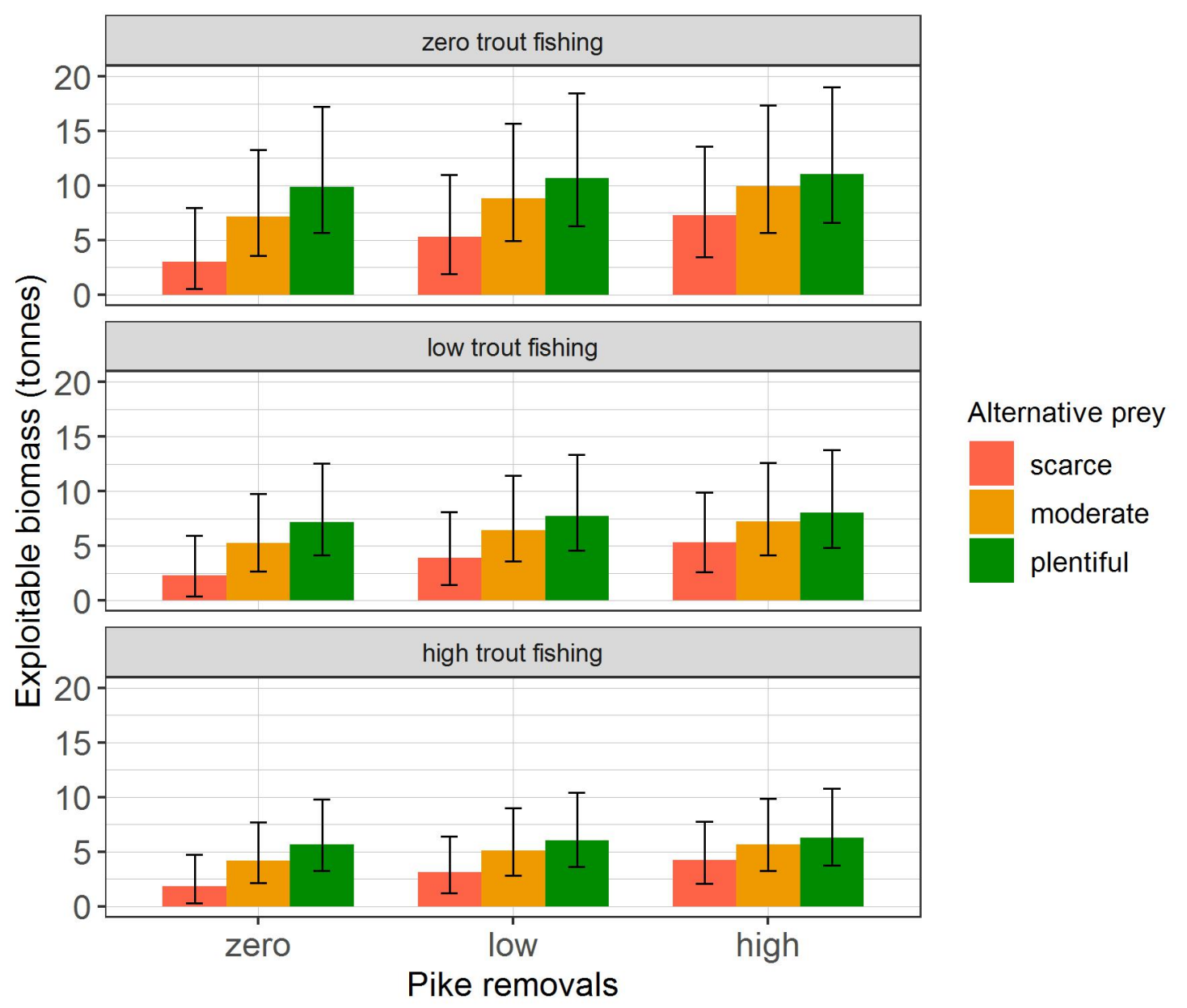

Figure 8: Exploitable trout biomass in different alternative prey biomass scenarios for three different pike removals and trout fishing pressures for the model configuration assuming insignificant adult pike cannibalism and equal vulnerability of trout and other prey to predation. Solid bars represent median outcomes and 'whiskers' represent $95 \%$ confidence intervals. 
were plentiful and no trout fishing occurred. This implies that pike removals may be an effective management tool in systems with little alternative prey, but may have a negligible effect on trout biomass in systems with abundant alternative prey. In the moderate alternative prey resource scenario, a greater than $15 \%$ increase in median trout biomass was observed when pike removals were increased from 'low' to 'high' in the context of 'low' trout fishing. However, an almost $25 \%$ increase in the median trout biomass was observed when the trout fishing level was reduced from high to low in the context of low pike removals. This suggests that, in the moderate alternative prey resource scenario, a considerable reduction in trout fishing mortality may be slightly more beneficial to trout populations than a similar increase in pike removals.

It is important to note that the confidence intervals indicated by the error bars were very wide in all cases. These wide error bars reflect the uncertainty in transporting stock-recruitment relationships from donor to recipient systems. The level of uncertainty observed in the current model outputs suggests that while the general trends can be accepted, i.e., the relative effects of different management actions, absolute levels of predicted trout biomass are less reliable. However, the model does provide an invaluable method for assessing the consequences of management actions in in relatively datalimited systems with poor catch records but robust indices of species abundance data providing realistic estimates of relative abundance.

Figure 9 illustrates the projected effects of pike removals on exploitable trout biomass in the presence of low trout angling pressure across the three ecosystem scenarios for three model configurations. The model configurations express two conflicting stakeholder beliefs and a compromise between them in terms of a combination of species vulnerabilities. Thus, we examine model outcomes for trout anglers' beliefs (pike prefer trout to alternative prey and do not cannibalise adult pike), pike anglers' beliefs (pike do not discriminate between trout, other prey and adult pike) and neutral beliefs (pike show no preference for trout or alternative prey but avoid eating adult pike). Results are arranged in a different manner compared to Figure 8 in order to emphasise the effects of pike removals. Harvestable trout biomass projections from the model configuration representing trout angler beliefs were smaller than other model configurations across the matrix of scenarios and beliefs. The greatest pike-removal induced increases in trout biomass were projected to occur in the model configuration depicting trout angler beliefs. These increases are particularly evident in the scarce alternative prey scenario and persist to a lesser degree for the moderate and plentiful alternative prey scenarios. The influence of adult cannibalism on the efficacy of pike removals were examined by comparing the projections of the model when configured to represent pike angler beliefs 


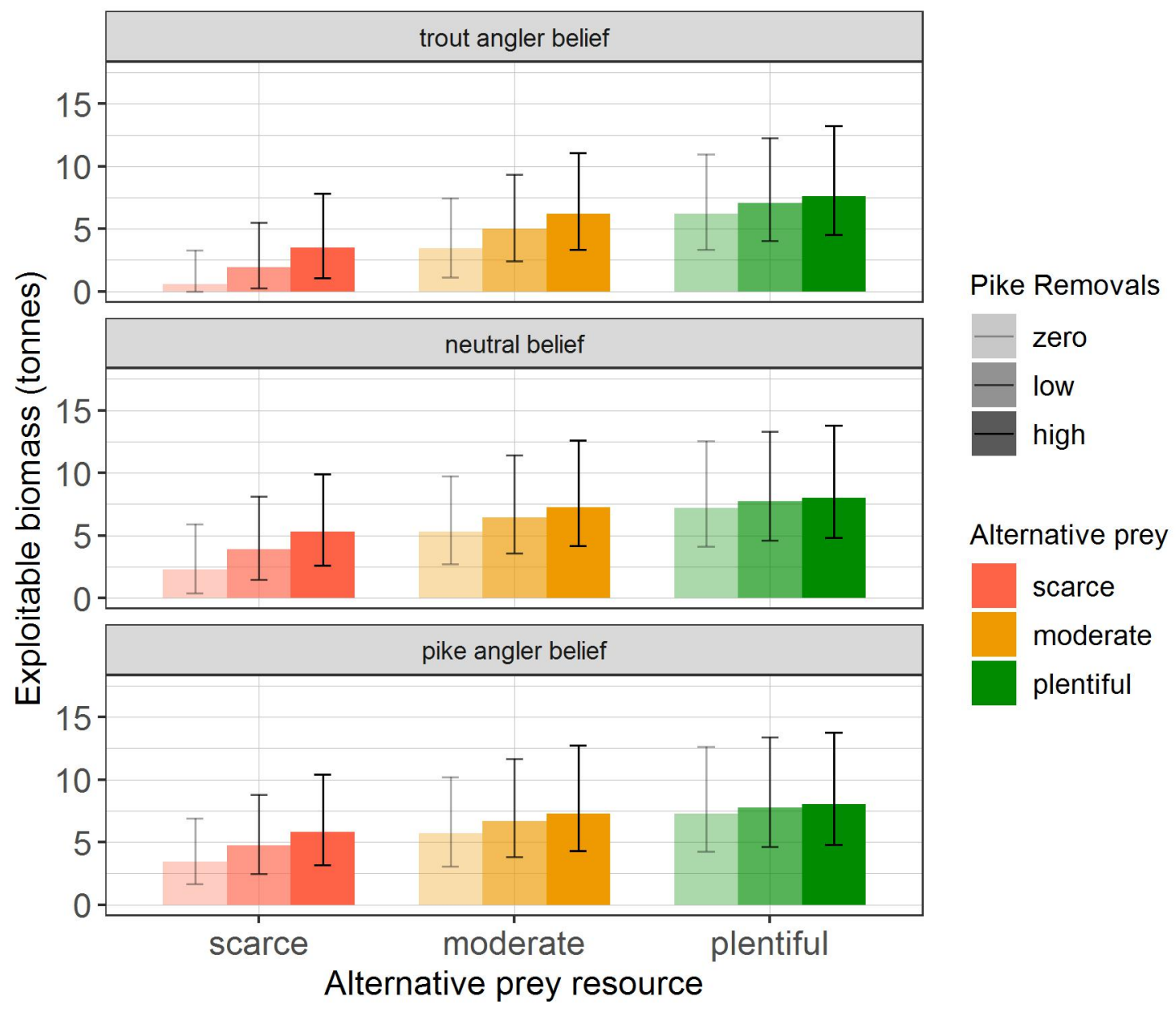

Figure 9: Exploitable trout biomass for a population experiencing low trout angling pressure in three different alternative prey biomass scenarios across three different pike removal levels for three model configurations corresponding to implicit trout angler, pike angler and neutral beliefs regarding pike, trout and other prey interactions. Solid bars represent median outcomes and 'whiskers' represent $95 \%$ confidence intervals. 
(cannibalism present) and neutral beliefs (cannibalism absent). For example, adult pike cannibalism was projected to reduce the benefits of introducing low pike removals from a $130 \%$ increase in trout biomass to a $65 \%$ increase in the scarce alternative prey situation. This corresponds to a significant alleviation in predation pressure as a result of intraspecific mortality when other prey are scarce. However, as other prey becomes more available such reductions in pike removal efficacy are diminished and the projections of the model configured to represent pike angler beliefs converge to those representing neutral beliefs.

Potential alternative prey biomasses in the scarce, moderate and plentiful scenarios are defined in terms of the theoretical biomass quantity $\kappa_{c}$. A more intuitive measure of potential alternative prey biomass may be obtained by expressing the biomass of alternative prey over the size range defined by the trout length classes (from $16 \mathrm{~cm}$ to $56 \mathrm{~cm}$ corresponding to individual body-masses from approximately $47 \mathrm{~g}$ to $1956 \mathrm{~g}$, respectively) relative to the steady-state aggregate biomass of trout. For example, the potential alternative prey biomasses in the scarce, moderate and plentiful scenarios are 2.4, 7.1 and 21.2 times greater than the median total trout biomass calculated in the moderate alternative prey scenario assuming low angling and management removals. As a reference, fish stock survey data from Lough Conn in 2016 (Kelly et al., 2017) shows that the biomass of other fish prey species is approximately 14 times greater than that of trout over the length range $(16 \mathrm{~cm}, 56 \mathrm{~cm})$.

\section{Discussion}

We presented a multi-species model within the framework of management scenario assessment in lake fisheries. This is a specific application of concepts that are widely-used in marine fisheries, but may not often have crossed over into inland systems (Beard et al. 2011; Cooke et al., 2014). As with stock assessment (Lorenzen et al., 2016, Fitzgerald et al., 2018), MSE concepts from marine fisheries science are likely to have broad application in inland fisheries and there is considerable scope for sharing across realms. Within lake fisheries, the Irish pike-trout example seems somewhat analogous to the case of Nile perch in Lake Victoria, where a single exploited top predator interacts with prey species that are also targeted by important fisheries (cf. e.g. Kitchell et al., 1997). Individual-based models (IBMs) (e.g. Hölker and Breckling, 2005) may provide a more natural modelling context for exploring the effects of environmental heterogeneity (both in space and time) on lake fish population dynamics. Model parameterisation is in theory more straightforward for IBMs than for stage-structured population models 
because IBMs incorporate simple rules describing individual behaviours often involving directly measurable parameters. However, IBMs often incorporate many behaviour rules and so are highly parameterised and require detailed quantitative information on individuals and their environment. Spatially-aggregated size class models provide a more appropriate level of detail for an exploration of population dynamics and the effect of management actions thereon in relatively data-limited environments. The model should be sufficiently general that it can be interpreted for application to other species and systems, and also extended to address alternative management scenarios.

The system studied clearly show multi-species interactions, size-dependent cannibalism and density dependence, all combining to create complex phenomena. Likely outcomes from different management scenarios, in terms of exploitable prey-fish populations, were not obvious and sometimes contradicted strongly-held stakeholder perceptions. The use of the size-structured population model with explicit predation mortality and alternative resources was well-justified as an objective framework. Subjecting the model to sensitivity and uncertainty analysis and using it in the framework of quantitative assessment of management actions enabled systematic exploration of the salient features of these complex systems. This in turn enabled us to present meaningful and convincing results to stakeholders.

Pike removal is a long-established management tool for trout fisheries in large Irish lakes predicated on historic evidence that trout form a significant component of pike diet (McLoone et al. 2019). However, the ecology of these lake systems has changed markedly in recent decades, with many locations experiencing eutrophication and invasion by a non-native prey fish roach. Furthermore, changes in angling patterns have seen pike become an important target species. In this context, it was necessary to review the removal programme, and heated stakeholder discussion yielded a set of candidate management strategies that could be evaluated. The size-structured multi-species model was used to examine a suite of management options to test a set of frequently-suggested strategies (pike removal and trout angling pressure) within the realm of particular stakeholder ecological beliefs. The model outcomes indicated that pike removal may enhance trout stocks in systems with little alternative prey, but is unlikely to be effective in most of the designated trout lakes due to colonization by roach. Realistic rates of trout angling were found to impose an important pressure on the modelled trout population. These conclusions and the associated model behaviours were found to be robust to realistic levels of uncertainty in influential model parameters such as those in the transported SR relationships. Our model provides a novel application of a management evaluation framework to inland systems, and can be generalised to lake fisheries which target mul- 
tiple interacting trophic levels.

The beliefs and opinions of fishery stakeholders were taken as informal inputs to model configurations and management scenarios in this study. Pike removals were projected to be most effective when incorporating beliefs held by certain trout anglers, that trout are more vulnerable to pike predation than other prey in the ecosystem and that adult pike cannibalism is insignificant, in the model. Adult pike cannibalism was observed to significantly alleviate predation pressure on trout when alternative prey was not plentiful. This is consistent with existing ecological theory which has shown that cannibalism stabilizes predator-prey systems (e.g. Kohlmeier and Ebenhöh, 1995) and empirical observations that cannibalism facilitates coexistence of predator prey populations (Ohlberger et al., 2012, Byström et al., 2013). An introduction or increase of pike removals was observed to improve trout biomass in all configurations although its effectiveness diminished with increasing biomasses of other prey.

In all cases, the model indicates that a greater biomass of alternative prey (in the same size range as trout) diminishes the predation mortality on trout, which modifies the potential utility of pike removal as a trout conservation tool. This effect has been observed empirically in one of the designated Irish trout lakes (Lough Sheelin), where non-native roach have become established (Shephard et al., 2018) and now constitute an important prey species for pike (Pedreschi et al., 2015). Model representation of ecosystem function is such that any reductions in predation pressure on trout lead to enhanced projected steady-state brown trout biomass. However, ecological theory and empirical studies suggest that that larger populations of prey species can be expected to exert a negative competitive influence on trout (Eloranta et al., 2016; Helland et al., 2011). Such an impact could be reduced by predation on roach by pike (e.g. Bregazzi and Kennedy, 1980), which can exert top-down control on roach populations in eutrophic lakes (Grimm and Backx, 1990; Prejs et al., 1994, Berg et al., 1997). However, the potential negative influence of the presence (or introduction) of a large biomass of competitor prey species and the subsequent effect of pike cropping cannot be described in the current implementation of our model. An additional mechanistic description of resource competition must be incorporated in the model framework to capture such competition-induced dynamics.

In many of the designated lakes roach are, from an ecological perspective, as important a component of the fish community as trout and pike and may influence the interactions and population dynamics of pike and trout (Shephard et al., 2018). Therefore, a more realistic description of the ecosystem within the current modelling framework would include roach as a dynamic ecosystem component. This will involve removing roach from the constant size spectrum representation of alternative prey and adopt- 
ing a dynamic length-structured representation instead. Such a model generalisation is straightforward in theory but it was considered unfeasible in practice because of the absence of reliable stock-recruitment data for invasive roach.

Model representation of the role of roach as a competitor prey species with trout requires careful consideration of the effects of resource competition on the respective species. An accurate description of competition for limited resources should allow resource depletion as consumer abundance increases. Resource depletion as a consequence of 'grazing pressure' might be represented as a steepening of the background spectrum slope in response to increases in roach (and trout) abundance. Therefore, the effect on trout of resource competition with roach (and vice versa) could be represented by relating the growth transition matrix $\boldsymbol{P}$ in Equation (1), or more specifically the underlying LVB growth parameters, to depletion of the background resource. A simple logistic relationship between the trout growth constant $k$ and the spectral slope $\lambda$ (dependent on roach abundance) could provide a preliminary model representation of interspecific competition. An elaboration of the ecosystem model to include a third (prey) species and the inclusion of a simple representation of resource competition between prey species should allow us to describe a richer set of population responses and interactions.

Our results also show that angling can be an important pressure on trout populations in large Irish lakes. We explored the effect of changing angling mortality; this outcome may be achieved by a reduced catch limit, but other length-based management regulations such as harvest slot limits or protected slot limits may produce greater numbers of harvestable fish (Post et al., 2003, Gwinn et al., 2015). These approaches can also be easily explored using our length-structured model. Furthermore, the model may be integrated into a formal MSE framework involving the inclusion of 'observation error' in a performance metric derived from model projections and feedback between this performance metric and management actions based on a harvest control rule applied at annual or multi-year intervals.

\section{Acknowledgements}

We are very grateful to Ian J. Winfield, Øystein Langangen, the Freshwater Biological Association (FBA) and the Centre for Ecology and Hydrology (CEH) for providing access to the Windermere pike stock-recruitment data. 


\section{A Appendix}

\section{A.1 Growth}

Mean growth of individuals in the population is represented using the deterministic LVB growth model (von Bertalanffy, 1938). The expected (annual) growth increment $\Delta L$ for an individual of length $L_{t}$ between year $t$ and $t+1$ is obtained by first expressing LVB growth model in difference equation form (Gulland, 1983) as

$$
\Delta L=\left(L_{\infty}-L_{t}\right)\left(1-e^{-k}\right)
$$

where $L_{\infty}$ and $k$ are the asymptotic length and Brody growth constant for the population. The population is structured by a sequence of $J$ length classes such that the $j^{\text {th }}$ length class is $\left(l_{j}^{l}, l_{j}^{u}\right)$ and $l_{j}^{u}=l_{j+1}^{l}$ for $j=1, \ldots, J-1$. Following Sullivan et al. (1990) if the average state of an individual in length class $j$ is assumed to be well represented by a fish of mid-interval length $l_{j}^{*}=\left(l_{j}^{l}+l_{j}^{u}\right) / 2$ then the mean annual growth increment for all fish in length class $j$ is

$$
\Delta \bar{L}_{j}=\left(L_{\infty}-l_{j}^{*}\right)\left(1-e^{-k}\right)
$$

Individual variability about the mean growth increment for the population is modelled using a gamma distribution (Sullivan et al., 1990; Quinn II and Deriso, 1999). As detailed by (Sullivan et al., 1990), the growth increment $x$ for an individual is represented by the probability density function

$$
g(x \mid \alpha, \theta)=\frac{1}{\theta^{\alpha} \Gamma(\alpha)} x^{\alpha-1} e^{-x / \theta},
$$

where $\alpha$ and $\theta$ are the shape and scale parameters, respectively. Tthe expected growth increment is $E(x)=\alpha \theta$ and the variance about the mean is $\operatorname{Var}(x)=\alpha \theta^{2}=\theta E(x)$. The scale parameter $\theta$, which determines the variance, is assumed to take the value 2 for all length classes for reasons of parsimony. Therefore, the distribution of growth increments for an individual in length class $j$ is determined by the shape parameter which is directly proportional to the mean growth increment $\alpha=E(x) / \theta=\Delta \bar{L}_{j} / \theta$. This parameterisation of the gamma distribution means the stochastic variability of growth within the population is determined by the LVB growth parameters and length classes through Equation A.3.

The expected proportion of individuals in length class $l$ transitioning to length class 
$m$ is calculated as

$$
P_{m, l}=\int_{l_{m}^{l}}^{l_{m}^{u}} g\left(x \mid \Delta \bar{L}_{l} / \theta, \theta\right) d x
$$

for $m>l$. The growth transition matrix $\boldsymbol{P}$ in the length-structured population dynamics Equation (1) may then be fully populated by calculating $P_{m, l}$ for $m>l$ according to this expression, applying the 'no shrinking' assumption for $m<l$, and the conservation of abundance rule $\sum_{m} P_{m, l}=1$ to derive $P_{l, l}$ for each $l$. Furthermore, any individuals entering a length class with mid-length greater than $L_{\infty}$ will remain in that length class.

\section{A.2 Extrapolation of stock and recruitment relationships}

Extrapolation from donor systems to recipient systems is more straightforward when spawning stock and juvenile recruitment are expressed in terms of densities, i.e. abundances per unit spawning habitat area. For example, dividing through the Beverton-Holt stock-recruitment relationship between juvenile recruitment $R$ and spawning stock $Y$ by the spawning habitat area $A$ gives

$$
r=\frac{a s}{1+b A s}=\frac{a s}{1+b^{\prime} s}
$$

where $r=R / A, s=Y / A$ and $b^{\prime}=b A$. Direct extrapolation from a donor to a recipient system is achieved by assuming that the SR dynamics are identical in both systems apart from differences in spawning habitat area. Therefore, recruitment $R$ in the recipient system is derived from spawner density $s=Y / A_{\text {rec }}$ and donor system parameters $a$ and $b^{\prime}=b A_{\text {don }}$ by applying

$$
R \equiv r A_{\mathrm{rec}}=\frac{a s A_{\mathrm{rec}}}{1+b^{\prime} s}=\frac{a Y}{1+b\left(A_{\mathrm{don}} / A_{\mathrm{rec}}\right) Y},
$$

where $Y$ and $A_{\text {rec }}$ denote spawning stock and spawning area for the recipient system.

\section{A.3 Stock and recruitment data}

Adult spawning stock and juvenile recruitment data for sea trout were derived from the fish trap monitoring data recorded in Burrishoole as reported by (Poole et al., 2007). Spawning stock was measured in terms of wild egg deposition and juvenile recruitment was defined as the abundance of downstream (spring-) spawning migrating smolts and 'unsilvered' autumn-migrating juveniles. Egg deposition estimates were derived from the reproductive parameter estimates for each sea age class (proportion of mature fish, proportion of females, mature female fecundity) and the annually estimated escapement 
structured by year class. Juvenile recruitment in subsequent years was matched to the parent brood year using smolt age- and unsilvered juvenile age-proportions to obtain a SR dataset. This was converted to density data using the habitat area estimate for Burrishoole (see Section A.4 for further details). A Beverton-Holt spawner-recruit model was fitted to the data assuming lognormal measurement error in the recruitment data, such that

$$
\log r \sim \log a+\log s-\log (1+b s)+\mathcal{N}\left(0, \sigma^{2}\right)
$$

where $r$ denotes recruitment density, $s$ denotes spawning stock density and $\mathcal{N}\left(0, \sigma^{2}\right)$ denotes a normal error term with variance $\sigma^{2}$, using a simple Metropolis-Hastings Markov chain Monte Carlo (MCMC) algorithm (see Hartig, 2010; Kruschke, 2015, for example). Broad priors for parameters $\log a$ and $b$ were estimated from a brief examination of the data and the proposal function was tuned to give relatively small steps using trial-anderror. Posterior distributions for $\log a$ and $b$ were derived from the remainder of a total chain of 100,000 iterations once the initial burn-in stage of 5,000 iterations was discarded.

The histogram of sample values from the posterior distribution of $\log a$ in the BevertonHolt model, obtained through the MCMC method and shown in Figure A.1 a, appeared to be approximately normal in shape. An analytical approximation to the posterior distribution was obtained by fitting a Gaussian curve to the histogram data. A normal distribution also provides a reasonable approximation to the posterior distribution for density-dependent SR parameter $b$ (Figure A.1 ). Examination of the MCMC trajectory through parameter space reveals a strong correlation between the density-independent parameter $\log a$ and the density-dependent parameter $b$. Such a correlation arises because the data constrains the plausible family of SR curves, e.g. a relatively large value of $\log a$ (initial slope of the stock-recruitment curve) requires a corresponding large value of $b$ (strong density dependence) to avoid overestimating maximum recruitment and vice versa. This parameter correlation was given by a simple linear relationship: $b=m \log a+c$ with a Gaussian error term $\mathcal{N}\left(0, \sigma_{b}^{2}\right)$, wherein $m=6.58 \times 10^{-5}$, $c=2.868 \times 10^{-4}$ and $\sigma_{b}=2.85 \times 10^{-6}$.

A similar Bayesian approach is adopted to fit a Ricker model to synthetic pike data calculated by Langangen et al. (2011) from a catch-at-age stock-assessment. Spawning stock was defined as the aggregate abundance of all adults (between 3 and 9 years of age) in year $t$ and recruitment was defined as the abundance of age 3 pike in year $t+3$. Stock-recruitment abundance data was converted to density data using the habitat area estimate (see Section A.4 for further details) for Windermere (Mortimer and Worthington, 1942). The density of recruits $r$ is proposed to have nonlinear, Ricker dependence 

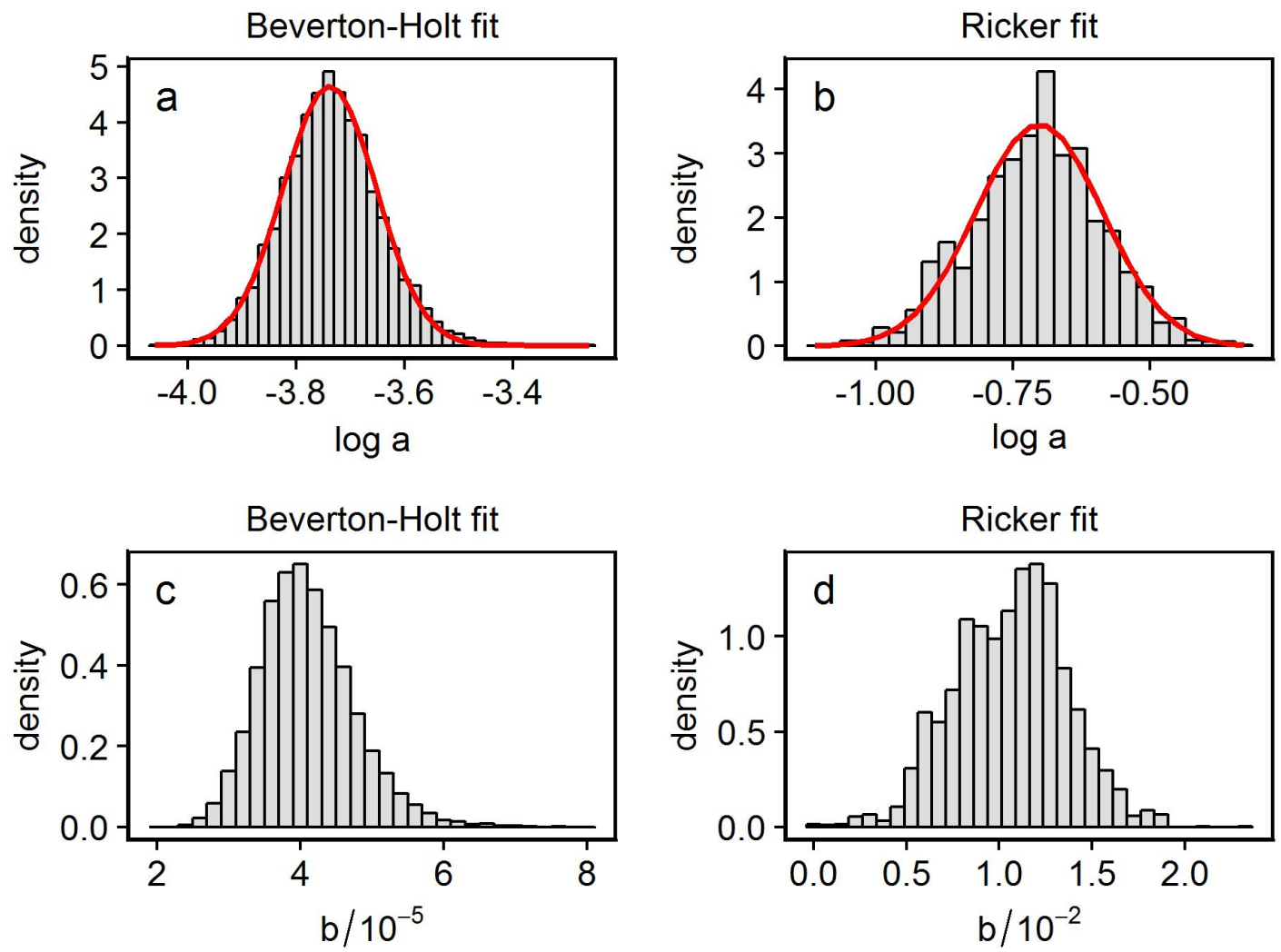

Figure A.1: Posterior distributions from Metropolis-Hastings fitting method for Beverton-Holt SR curve applied to Burrishoole sea-trout data (Poole et al., 2007) (a and c) and Ricker SR curve applied to Windermere pike data (Langangen et al., 2011) ( $b$ and $d)$. The red lines indicate Gaussian curve fits 


\begin{tabular}{llll}
\hline Population & & Burrishoole sea trout & Windermere pike \\
\hline \multirow{2}{*}{$a \sim \mathcal{N}\left(\mu_{a}, \sigma_{a}\right)$} & $\mu_{a}$ & -3.733 & -0.703 \\
& $\sigma_{a}$ & 0.085 & 0.11 \\
$b \sim m \log a+c+$ & $m$ & $6.58 \times 10^{-5}$ & $2.21 \times 10^{-2}$ \\
$\mathcal{N}\left(0, \sigma_{b}\right)$ & $c$ & $2.868 \times 10^{-4}$ & $2.62 \times 10^{-2}$ \\
& $\sigma_{b}$ & $2.85 \times 10^{-6}$ & $1.61 \times 10^{-3}$ \\
\hline
\end{tabular}

Table 5: Posterior distributions parameterisations for density-independent $(\log a)$ and density-dependent $(b)$ stock-recruitment parameters from Bayesian inference of sea trout (Poole et al., 2007) and pike data (Langangen et al., 2011).

on adult stock density $s$ subject to lognormal error, i.e.

$$
\log r \sim \log a+\log s-b s+\mathcal{N}\left(0, \sigma^{2}\right)
$$

and the same Metropolis-Hastings algorithm as used for sea trout recruitment was used to derive posterior distributions for $\log a, b$ (and $\sigma$ ).

The posterior distributions for the SR parameters $\log a$ and $b$ were once again observed to be approximately normal in shape. Mean and variance parameters for the normal distribution representing $\log a$ were obtained by fitting a Gaussian curve to the sampled posterior histogram data obtained from the Metropolis-Hastings algorithm. A linear correlation was also inferred to exist between $\log a$ and $b$ from the MCMC iterations with a slope of $m=2.21 \times 10^{-2}$, an intercept of $c=2.62 \times 10^{-2}$ and a normal error term with a standard deviation of $\sigma_{b}=1.61 \times 10^{-3}$.

Table 5 shows the mean and variance of the fitted normal distributions for the densityindependent $\log a$, the slope and intercept parameters for the linear correlation between $\log a$ and $b$ and the variance $\sigma_{b}$ of the error term in this correlation for both species. In the uncertainty analysis random realisations of stock-recruitment parameters for either sea trout or northern pike data were obtained by first drawing a $\log a$ value from the fitted normal distribution, deriving the correlated $b$ value from the normal distribution $b \sim \mathcal{N}\left(m \log a+c, \sigma_{b}^{2}\right)$ with the expected value linearly dependent on $\log a$ and a variance $\sigma_{b}^{2}$, and back-transforming the $\log a$ parameter to give the biological density-independent term $a$. 


\section{A.4 Spawning habitat areas for donor and recipient populations}

River-lake migratory (adfluvial) brown trout migrate from freshwater lakes, which provide adequate food resources for adult growth, to small streams connected to freshwater lakes to spawn (Milner et al., 2003, Ferguson et al., 2017). Herein, it is assumed that brown trout spawn only in rivers and streams - lake-spawning populations are relatively rare (Klemetsen et al., 2003) - so that the extent of the spawning habitat is measured through the wetted fluvial area. The Burrishoole system comprises a large network of shallow streams (and three lakes). The accessible fluvial area for this donor system was calculated to be approximately $A_{\text {don }}=12.5$ ha using the ArcGIS 10.3.1 software (ESRI, 2011), based on a predictive model developed by (McGinnity et al., 2012) for salmon but modified to include first order stream contributions.

An accurate estimate of the most likely recipient-to-donor system habitat area ratio $A_{\text {rec }} / A_{\text {don }}$ and the associated uncertainty around this estimate required a combination of data and judgment. It was considered important to provide a full account of uncertainty in habitat areas estimates because underestimation of the uncertainty in direct extrapolations of SR relationships has been noted as a common problem (Prévost et al., 2003). For example, a GIS analysis (ESRI, 2011) of the accessible fluvial area contributions (first order stream inclusive) of Lough Conn's primary 'feeder' streams indicates a total spawning habitat area of 107.3 ha. The River Deel - a large drainage comprising a network of smaller streams in the upper section and wider confluence in the lower section - contributes approximately $87.6 \%$ of the total accessible fluvial area. However, a genetic stock identification (GSI) study of brown trout in the Moy catchment including Loughs Conn and Cullin (Bradley et al., 2018) revealed that the River Deel contributes only $\approx 38.5 \%$ of the adult Lough Conn population. Uncertainty in the exact nature of the nursery stream contributions to juvenile recruitment in Lough Conn and, indeed, Burrishoole can be accounted for by proposing a distribution of plausible values for the SR extrapolation term $a_{\text {ratio }}=A_{\text {rec }} / A_{\text {don }}$.

First, a point estimate for an effective fluvial habitat area accessible to lake-migratory trout in the recipient system $A_{\text {rec }}$ was calculated. Estimation of the effective area attempted to reflect the disproportionally small contribution of the Deel habitat to the adult lake stock. A rudimentary correction was adopted. First it was noted that the other streams and rivers contribute $A_{\text {stream }} \approx 13.3$ ha of fluvial accessible area producing $p_{\text {stream }} \approx 61.5 \%$ of total adult stock. Thus, the effective River Deel habitat area must be $A_{\text {stream }} \times\left(1-p_{\text {stream }}\right) / p_{\text {stream }}=8.3$ ha assuming juvenile production in other streams is in some sense standard and comparable to the donor Burrishoole system. Total effective 
accessible fluvial habitat area in Lough Conn was $A_{\text {rec }} \approx 21.6$ ha. In order to encapsulate our beliefs about the uncertainty in the SR extrapolation process, we sought to represent the area ratio term $a_{\text {ratio }}$ as a probability distribution with a most likely value around the point estimate $a_{\text {ratio, } 0}=21.6 / 12.5 \simeq 1.7$ and reasonable credibility for values between 1 and 3 . For convenience, the habitat area ratio estimates were assumed to be lognormally distributed such that random variable $\log a_{\text {ratio }}$ had a mean $\log a_{\text {ratio, } 0}$ and a variance of $0.25^{2}$. Thus, despite a detailed examination of the habitat area, for the purposes of uncertainty analysis the possible habitat area ratio vales are largely based on judgement and so the process may be generalised to other stock projection analyses.

Extrapolation of the northern pike stock-recruitment relationship from the donor (Windermere) to the recipient (Conn) lake also requires an estimate of the ratio of spawning and nursery habitat area available in each lake. Suitable spawning and nursery habitat for pike is most easily defined by depth ranges (Minns et al., 1996) although weed or vegetation coverage is widely known to be important for pike spawning (Casselman and Lewis, 1996, Grimm, 1981). Shallow depth ranges better define potential spawning habitat area whereas vegetation coverage within these shallows define realisable spawning habitat. However, vegetation coverage is much more difficult to quantify across systems and so we defined pike spawning and nursery habitat area to correspond to areas of lakes with depths of less than two metres. The 'donor' habitat area of Windermere with water depths less than two metres has been estimated to be $A_{\text {don }}=202$ ha from a total lake area of 1482 ha (Mortimer and Worthington, 1942). There was significant uncertainty regarding the extent of vegetation coverage in this potential spawning habitat area.

An estimate of the area of Lough Conn with water depth less than two metres was calculated from national lake polygon and digital terrain model datasets using ArcGIS (ESRI, 2011). Of the total wetted surface area of approximately 4700 ha, Lough Conn has approximately 1330 ha of water with depths less than two metres. Champ and King, 1988) noted limited rooted weed coverage in Lough Conn ("being largely confined to shallow sheltered bays") consistent with the apparent link between northern pike abundance and aquatic vegetation (Grimm, 1981). Suitable spawning and nursery habitat is not adequately quantified by water depth alone; the presence or absence of extensive weed coverage introduces a large uncertainty in the extrapolation process. Based on abundance estimates from the Windermere stock-assessment (Langangen et al. (2011) estimated pike numbers between 5,000 and 15,000 over the last thirty years) and historic annual pike removal data for Conn (maximum of 1,073 between 1963 and 1969 when effort was high) we concluded that pike recruitment in Lough Conn should be similar to Windermere. Therefore, we proposed a lognormal pike spawning habitat area 
ratio distribution such that $\log a_{\text {ratio }}$ has a mean of $\log 1$ and variance of $0.4^{2}$.

\section{A.5 Alternative prey biomass size spectrum}

The biomass size spectrum defined in Equation (7) expresses the distribution of the ecosystem biomass with organism body mass according to a two-parameter power law relationship. These parameters, the ecosystem richness $\kappa_{c}$ and spectrum exponent $\lambda$, may be estimated from empirical observations (catch or survey data) according to the method described by Sweeting et al. (2009) and Emmrich et al. (2011). This method involves 'binning' individual body masses into logarithmic size classes and regressing the log-transformed normalised biomasses in each bin against the log-transformed average body mass. The discretised form of the biomass size spectrum relationship used for empirical estimation of the spectrum parameters is derived from Equation (7) by first integrating $B(m)$ over generic logarithmic size class $\left(m_{0}, a m_{0}\right)$, then dividing by the size class width $m_{0}$, and finally log-transforming the entire equation. If octave size classes $(a=2)$ are used then we obtain

$$
\log _{2}\left(\frac{\Delta B}{m_{0}}\right)=\log _{2}\left(\frac{\kappa_{c}}{2-\lambda} 2^{2-\lambda}-1\right)+(1-\lambda) \log _{2} m_{0},
$$

where $\Delta B=\int_{m_{0}}^{2 m_{0}} B d m$ is the total 'binned' biomass in size class $\left(m_{0}, 2 m_{0}\right)$. In the empirical treatment of survey data, a minimum size is specified (e.g. $m_{0}=0.5 \mathrm{~g}$ corresponding to the log size class -1) and the log-transformed normalised biomass in each size class is plotted against the $\log 2 m_{0}$. It is straightforward to determine the spectrum exponent from the slope $1-\lambda$ of the corresponding linear regression. The ecosystem richness parameter may be derived from the estimates of the intercept and the slope.

The biomass spectrum exponent, which gives the shape of the biomass distribution, may be empirically estimated from whole lake fish stock survey data as described above. However, relative indices of abundance cannot be used to estimate the absolute ecosystem richness $\kappa_{c}$. Therefore, it was necessary to estimate an approximate scaling factor relating the fish stock survey biomasses to absolute lake biomasses. This approximate scaling factor was determined from a surplus production estimate for exploitable brown trout biomass on Lough Conn Fitzgerald et al. (2018). The Lough Conn brown trout fishery has a minimum size limit of $30 \mathrm{~cm}$ and the median surplus production estimate of exploitable brown trout biomass, time-averaged over the period $1975-2001$, is $2,950 \times 10^{3} \mathrm{~g}$. In the 2016 CEN standard fish community survey of Lough Conn (Kelly et al., 2017) the biomass of exploitable trout was $2876 \mathrm{~g}$ out of a potential brown trout biomass of 
5373 g. Therefore, the CEN survey exploitable trout biomass represents approximately one thousandth of the estimated absolute fishable brown trout stock biomass. This scaling factor, derived from trout survey data, was assumed to hold for all species surveyed. Thus, the binned biomasses $\Delta B$ for each size class were increased by a factor of approximately one thousand before estimating $\kappa_{c}$ from the linear regression intercept.

\section{References}

Andersen, K. H., Beyer, J. E., 2006. Asymptotic size determines species abundance in the marine size spectrum. The American Naturalist 168 (1), 54-61, Associate Editor and Editor: Donald L. DeAngelis.

doi:10.1086/504849

Andersen, K. H., Jacobsen, N. S., Farnsworth, K. D., 2016. The theoretical foundations for size spectrum models of fish communities. Canadian Journal of Fisheries and Aquatic Sciences 73 (4), 575-588.

doi:10.1139/cjfas-2015-0230

Andersen, K. P., Ursin, E., 1977. A multispecies extension to the Beverton and Holt theory of fishing, with accounts of phosphorus circulation and primary production. Meddelelser fra Danmarks Fiskeri- og Havundersøgelser. N.S. Danish Institute for Fishery and Marine Research.

URL https://books .google .ie/books?id=9-LxcQAACAAJ

Beard, T. D., Arlinghaus, R., Cooke, S. J., McIntyre, P. B., De Silva, S., Bartley, D., Cowx, I. G., 2011. Ecosystem approach to inland fisheries: research needs and implementation strategies. Biology Letters.

doi:10.1098/rsbl.2011.0046

Berg, S., Jeppesen, E., Søndergaard, M., 1997. Pike (Esox lucius L.) stocking as a biomanipulation tool 1. Effects on the fish population in Lake Lyng, Denmark. Springer Netherlands, Dordrecht, pp. 311-318.

URL https://doi .org/10.1007/978-94-011-5648-6_32

Beverton, R. J. H., Holt, S. J., 1957. On the Dynamics of Exploited Fish Populations. Springer Netherlands.

URL http://dx.doi .org/10.1007/978-94-011-2106-4 
Beyer, J. E., 1989. Recruitment stability and survival - simple size-specific theory with examples from the early life dynamic of marine fish. Dana 7, 45-147.

Bracken, J. J., 1973. The age and growth of pike from Irish trout rivers. Irish Fisheries Investigations, Series A (Freshwater) (12).

Bradley, C., Hynes, R., Prodöhl, P., Delanty, K., Kelly, F. L., O’Grady, M., 2018. Population structuring and Genetic Stock Identification of sea running and lake-river migratory trout (Salmo trutta) from the Moy Catchment.

Bregazzi, P. R., Kennedy, C. R., 1980. The biology of pike, Esox lucius 1., in a southern eutrophic lake. Journal of Fish Biology 17 (1), 91-112.

doi:10.1111/j.1095-8649.1980.tb02745.x

Butterworth, D. S., 2007. Why a management procedure approach? Some positives and negatives. ICES Journal of Marine Science 64 (4), 613-617.

doi:10.1093/icesjms/fsm003

Butterworth, D. S., Plagányi, É. E., 2004. A brief introduction to some approaches to multispecies/ecosystem modelling in the context of their possible application in the management of south african fisheries. African Journal of Marine Science 26 (1), 5361.

doi:10.2989/18142320409504049

Butterworth, D. S., Punt, A. E., 1999. Experiences in the evaluation and implementation of management procedures. ICES Journal of Marine Science 56, 985-998.

doi:10.1006/jmsc.1999.0532

Byström, P., Ask, P., Andersson, J., Persson, L., 07 2013. Preference for cannibalism and ontogenetic constraints in competitive ability of piscivorous top predators. PLOS ONE $8(7), 1-7$.

doi:10.1371/journal.pone.0070404

Byström, P., Karlsson, J., Nilsson, P., Van Kooten, T., Ask, J., Olofsson, F., 2007. Substitution of top predators: effects of pike invasion in a subarctic lake. Freshwater Biology 52 (7), 1271-1280. doi:10.1111/j.1365-2427.2007.01763.x

Casselman, J. M., Lewis, C. A., 1996. Habitat requirements of northern pike (Esox lucius). Canadian Journal of Fisheries and Aquatic Sciences 53 (S1), 161-174.

doi: $10.1139 /$ f96-019 
Caswell, H., 2001. Matrix Population Models: Construction, Analysis, and Interpretation, 2nd Edition. Sinauer Associates.

URL https://books .google.ie/books?id=CPsTAQAAIAAJ

Champ, W., King, J. J., 1988. The trophic status of Lough Conn: an extended study. Tech. rep., Central Fisheries Board.

Champ, W. S. T., 1998. Eutrophication in Irish Waters. Royal Irish Academy, Ch. Phosphourous/chlorophyll relationships in selected Irish lakes: ecological consequences and suggested criteria for ecosystem mangement, pp. 91-105.

Claessen, D., de Roos, A. M., Persson, L., 2004. Population dynamic theory of size-dependent cannibalism. Proceedings of the Royal Society of London B: Biological Sciences 271 (1537), 333-340.

doi: $10.1098 / \mathrm{rspb} .2003 .2555$

Collie, J. S., Botsford, L. W., Hastings, A., Kaplan, I. C., Largier, J. L., Livingston, P. A., Plagányi, É., Rose, K. A., Wells, B. K., Werner, F. E., 2016. Ecosystem models for fisheries management: finding the sweet spot. Fish and Fisheries 17 (1), 101-125. doi $10.1111 /$ faf. 12093

Cooke, S. J., Arlinghaus, R., Bartley, D. M., Beard, T. D., Cowx, I. G., Essington, T. E., Jensen, O. P., Lynch, A., Taylor, W. W., Watson, R., 2014. Where the waters meet: sharing ideas and experiences between inland and marine realms to promote sustainable fisheries management. Canadian Journal of Fisheries and Aquatic Sciences 71 (10), 1593-1601.

doi:10.1139/cjfas-2014-0176

Curtis, J., 2018. Pike (Esox lucius) stock management in designated brown trout (Salmo trutta) fisheries: Anglers' preferences. Fisheries Research 207, 37 - 48.

doi:10.1016/j.fishres.2018.05.020

Deriso, R. B., jul 1982. Relationship of fishing mortality to natural mortality and growth at the level of maximum sustainable yield. Canadian Journal of Fisheries and Aquatic Sciences 39 (7), 1054-1058.

doi:10.1139/f82-141

Drouineau, H., Mahévas, S., Bertignac, M., Fertin, A., 2008. Assessing the impact of discretisation assumptions in a length-structured population growth model. Fisheries 
Research 91 (2), 160 - 167.

doi:10.1016/j.fishres.2007.11.017

Eloranta, A. P., Helland, I. P., Sandlund, O. T., Hesthagen, T., Ugedal, O., Finstad, A. G., 2016. Community structure influences species' abundance along environmental gradients. Journal of Animal Ecology 85 (1), 273-282.

doi: $10.1111 / 1365-2656.12461$

Emmrich, M., Brucet, S., Ritterbusch, D., Mehner, T., 2011. Size spectra of lake fish assemblages: responses along gradients of general environmental factors and intensity of lake-use. Freshwater Biology 56 (11), 2316-2333.

doi:10.1111/j.1365-2427.2011.02658.x

ESRI, 2011. ArcGIS Desktop: Release 10.3.1. Environmental Systems Research Institute, Redlands, CA, 10th Edition.

Ferguson, A., Reed, T. E., McGinnity, P., Prodohl, P. A., 2017. Sea Trout: Science \& Management: Proceedings of the 2nd International Sea Trout Symposium. Troubador Publishing, Ch. Anadromy in brown trout (Salmo trutta): A review of the relative roles of genes and environmental factors and the implications for management and conservation.

URL https://www.ebook.de/de/product/32621482/graeme_harris_sea_trout_ science_management.html

Fitzgerald, C. J., Delanty, K., Shephard, S., 2018. Inland fish stock assessment: Applying data-poor methods from marine systems. Fisheries Management and Ecology 25 (4), 240-252.

doi:10.1111/fme.12284

Floeter, J., Temming, A., 2003. Explaining diet composition of North Sea cod (Gadus morhua): prey size preference vs. prey availability. Canadian Journal of Fisheries and Aquatic Sciences 60 (2), 140-150.

doi:10.1139/f03-007

Floeter, J., Temming, A., 2005. Analysis of prey size preference of North Sea whiting, saithe, and grey gurnard. ICES Journal of Marine Science 62 (5), 897-907.

doi:10.1016/j.icesjms.2005.03.004

Frank, K. T., Petrie, B., Choi, J. S., Leggett, W. C., 2005. Trophic cascades in a formerly 
cod-dominated ecosystem. Science 308 (5728), 1621-1623.

doi:10.1126/science.1113075

Gargan, P. G., O'Grady, M. F., 1992. Feeding relationships of trout Salmo trutta L., Perch Perca fluviatilis L. and Roach Rutilus rutilus (L.) in Lough Sheelin, Ireland. Irish Fisheries Investigations, Series A (Freshwater) (35).

Garrison, L. P., Link, J. S., Kilduff, D. P., Cieri, M. D., Muffley, B., Vaughan, D. S., Sharov, A., Mahmoudi, B., Latour, R. J., 2010. An expansion of the msvpa approach for quantifying predator-prey interactions in exploited fish communities. ICES Journal of Marine Science 67 (5), 856-870.

doi:10.1093/icesjms/fsq005

Gislason, H., Daan, N., Rice, J. C., Pope, J. G., 2010. Size, growth, temperature and the natural mortality of marine fish. Fish and Fisheries 11 (2), 149-158.

doi:10.1111/j.1467-2979.2009.00350.x

Gislason, H., Helgason, T., 1985. Species interaction in assessments of fish stocks with special application to the North Sea. Dana 5, 1-44.

Grimm, M. P., 1981. The composition of northern pike (Esox lucius L.) populations in four shallow waters in the Netherlands, with special reference to factors influencing $0+$ pike biomass. Aquaculture Research 12 (2), 61-76.

doi:10.1111/j.1365-2109.1981.tb00011.x

Grimm, M. P., Backx, J. J. G. M., Aug 1990. The restoration of shallow eutrophic lakes, and the role of northern pike, aquatic vegetation and nutrient concentration. Hydrobiologia 200 (1), 557-566.

doi:10.1007/BF02530373

Guiet, J., Poggiale, J.-C., Maury, O., 2016. Modelling the community size-spectrum: recent developments and new directions. Ecological Modelling 337, 4- 14. doi:10.1016/j.ecolmodel.2016.05.015

Gulland, J. A., 1983. Fish Stock Assessment: A Manual of Basic Methods. (FAO/Wiley Series on Food Agriculture). Wiley.

Gwinn, D. C., Allen, M. S., Johnston, F. D., Brown, P., Todd, C. R., Arlinghaus, R., 2015. Rethinking length-based fisheries regulations: the value of protecting old and large fish with harvest slots. Fish and Fisheries 16 (2), 259-281.

doi:10.1111/faf.12053 
Haapasaari, P., Michielsens, C. G. J., Karjalainen, T. P., Reinikainen, K., Kuikka, S., 2007. Management measures and fishers' commitment to sustainable exploitation: a case study of atlantic salmon fisheries in the baltic sea. ICES Journal of Marine Science $64(4), 825-833$.

doi:10.1093/icesjms/fsm002

Hartig, F., Sep. 2010. A simple Metropolis-Hastings MCMC in R, unpublished.

URL https://theoreticalecology.wordpress.com/2010/09/17/metropolishastings-mcmc-in-r/

Haught, S., von Hippel, F. A., Sep 2011. Invasive pike establishment in cook inlet basin lakes, alaska: diet, native fish abundance and lake environment. Biological Invasions 13 (9), 2103-2114.

doi:10.1007/s10530-011-0029-4

Healy, A., 1956. Pike (Esox lucius L.) in three Irish lakes. Scientific Proceedings of the Royal Dublin Society 27, 51-63.

Heikinheimo, O., Korhonen, A. P., 1996. Food consumption of northern pike (Esox lucius L.), estimated with a bioenergetics model. Ecology of Freshwater Fish 5 (1), 37-47. doi: $10.1111 / \mathrm{j} .1600-0633.1996 . t b 00035 . x$

Hein, C. L., Öhlund, G., Englund, G., 2014. Fish introductions reveal the temperature dependence of species interactions. Proceedings of the Royal Society of London B: Biological Sciences 281 (1775).

doi:10.1098/rspb.2013.2641

Helgason, T., Gislason, H., 1979. VPA analysis with species interaction due to predation. ICES C.M. G:52, 10 pp.

Helland, I. P., Finstad, A. G., Forseth, T., Hesthagen, T., Ugedal, O., dec 2011. Icecover effects on competitive interactions between two fish species. Journal of Animal Ecology $80(3), 539-547$.

doi:10.1111/j.1365-2656.2010.01793.x

Hesthagen, T., Sandlund, O. T., Finstad, A. G., Johnsen, B. O., 2015. The impact of introduced pike (Esox lucius L.) on allopatric brown trout (Salmo trutta L.) in a small stream. Hydrobiologia 744 (1), 223-233.

doi:10.1007/s10750-014-2078-z 
Hilborn, R., Amoroso, R. O., Bogazzi, E., Jensen, O. P., Parma, A. M., Szuwalski, C., Walters, C. J., 2017. When does fishing forage species affect their predators? Fisheries Research 191, $211-221$.

doi:10.1016/j.fishres.2017.01.008

Hoenig, J. M., 1983. Empirical use of longevity data to estimate mortality rates. Fishery Bulletin 82, 898-903.

Hölker, F., Breckling, B., 2005. A spatiotemporal individual-based fish model to investigate emergent properties at the organismal and the population level. Ecological Modelling 186 (4), 406 - 426, emergent Properties in Individual-based Models Case Studies from the Bornhved Project (Northern Germany).

doi:https://doi.org/10.1016/j.ecolmodel.2005.02.010

Hoogland, R., Tinbergen, N., Morris, D., jan 1956. The spines of sticklebacks (Gasterosteus and Pygosteus) as means of defence against predators (Perca and Esox). Behaviour 10 (1), 205-236.

doi:10.1163/156853956X00156

Houle, J. E., Andersen, K. H., Farnsworth, K. D., Reid, D. G., 2013. Emerging asymmetric interactions between forage and predator fisheries impose management trade-offsa. Journal of Fish Biology 83 (4), 890-904.

doi: $10.1111 / \mathrm{jfb} .12163$

Hunsicker, M. E., Ciannelli, L., Bailey, K. M., Buckel, J. A., Wilson White, J., Link, J. S., Essington, T. E., Gaichas, S., Anderson, T. W., Brodeur, R. D., Chan, K.-S., Chen, K., Englund, G., Frank, K. T., Freitas, V., Hixon, M. A., Hurst, T., Johnson, D. W., Kitchell, J. F., Reese, D., Rose, G. A., Sjodin, H., Sydeman, W. J., van der Veer, H. W., Vollset, K., Zador, S., 2011. Functional responses and scaling in predatorprey interactions of marine fishes: contemporary issues and emerging concepts. Ecology Letters 14 (12), 1288-1299.

doi: $10.1111 / \mathrm{j} .1461-0248.2011 .01696 \cdot \mathrm{x}$

IFI, 2015a. The economic contribution of brown trout angling in Ireland, unpublished National Strategy for Angling Development (NSAD) document.

URL https://wWw.fisheriesireland.ie/documents/530-the-economiccontribution-of-brown-trout-angling-in-ireland.html

IFI, 2015b. The economic contribution of pike angling in Ireland, unpublished National Strategy for Angling Development Document. 
URL https://www.fisheriesireland.ie/documents/528-the-economiccontribution-of-pike-angling-in-ireland.html

Jacobsen, N. S., Gislason, H., Andersen, K. H., dec 2013. The consequences of balanced harvesting of fish communities. Proceedings of the Royal Society B: Biological Sciences 281 (1775), 20132701-20132701.

doi:10.1098/rspb.2013.2701

Kelly, F. L., Connor, L., Delanty, K., McLoone, P., Coyne, J., Morrissey, E., Corcoran, W., Cierpial, D., Matson, R., Gordon, P., O’Briain, R., Rocks, K., O'Reilly, S., Kelly, K., Puttharee, D., McWeeney, D., Robson, S., Buckley, S., 2017. Fish Stock Survey of Lough Conn, August 2016. resreport IFI/2017/1-4352, Inland Fisheries Ireland.

Kennedy, M., 1969. Irish pike investigations. 1. Spawning and early life history. Irish Fisheries Investigations, Series A (Freshwater) 5, 4-33.

Kitchell, J. F., Schindler, D. E., Ogutu-Ohwayo, R., Reinthal, P. N., 1997. The Nile perch in Lake Victoria: interactions between predation and fisheries. Ecological Applications 7 (2), 653-664.

doi:10.1890/1051-0761(1997)007[0653:TNPILV]2.0.CO;2

Klemetsen, A., Amundsen, P.-A., Dempson, J. B., Jonsson, B., Jonsson, N., O'Connell, M. F., Mortensen, E., 2003. Atlantic salmon salmo salar 1., brown trout salmo trutta 1. and arctic charr salvelinus alpinus (1.): a review of aspects of their life histories. Ecology of Freshwater Fish 12 (1), 1-59.

doi: $10.1034 / \mathrm{j} .1600-0633.2003 .00010 \cdot \mathrm{x}$

Kohlmeier, C., Ebenhöh, W., May 1995. The stabilizing role of cannibalism in a predatorprey system. Bulletin of Mathematical Biology 57 (3), 401-411. doi:10.1007/BF02460632

Kruschke, J. K., 2015. Doing Bayesian data analysis: a tutorial with R, JAGS, and Stan, 2nd Edition. Academic Press, Oxford, UK.

URL https://www.ebook.de/de/product/22836901/john_k_kruschke_doing_ bayesian_data_analysis.html

Langangen, Ø., Edeline, E., Ohlberger, J., Winfield, I. J., Fletcher, J. M., James, J. B., Stenseth, N. C., Vøllestad, L. A., 2011. Six decades of pike and perch population dynamics in Windermere. Fisheries Research 109 (1), 131 - 139.

doi:10.1016/j.fishres.2011.01.029 
Langsdale, S., 9 2008. Communication of climate change uncertainty to stakeholders using the scenario approach. Journal of Contemporary Water Research \& Education 140 (1), 24-29.

doi: $10.1111 / \mathrm{j} .1936-704 \mathrm{X} .2008 .00025 . \mathrm{x}$

Larkin, P. A., 1979. Predator-Prey Systems in Fisheries Management. Sport Fishing Institute, Washington DC, Ch. Predator-prey relations in fishes: an overview of the theory, pp. 13-22.

Link, J. S., Lucey, S. M., Melgey, J. H., 2012. Examining cannibalism in relation to recruitment of silver hake Merluccius bilinearis in the U.S. northwest Atlantic. Fisheries Research 114, 31 - 41, biology, Harvesting, Management and Conservation of Hakes. doi:10.1016/j.fishres.2011.04.022

Lorenzen, K., Cowx, I. G., Entsua-Mensah, R. E. M., Lester, N. P., Koehn, J. D., Randall, R. G., So, N., Bonar, S. A., Bunnell, D. B., Venturelli, P., Bower, S. D., Cooke, S. J., Sep 2016. Stock assessment in inland fisheries: a foundation for sustainable use and conservation. Reviews in Fish Biology and Fisheries 26 (3), 405-440.

doi:10.1007/s11160-016-9435-0

Magnusson, A., Punt, A. E., Hilborn, R., 2013. Measuring uncertainty in fisheries stock assessment: the delta method, bootstrap, and MCMC. Fish and Fisheries 14 (3), 325342 .

doi: $10.1111 / j .1467-2979.2012 .00473 . x$

McGinnity, P., De Eyto, E., Gilbey, J., Gargan, P., Roche, W., Stafford, T., McGarrigle, M., Ó' Maoiléidigh, N., Mills, P., 2012. A predictive model for estimating river habitat area using GIS-derived catchment and river variables. Fisheries Management and Ecology 19 (1), 69-77.

doi: $10.1111 / \mathrm{j} .1365-2400.2011 .00820 \cdot \mathrm{x}$

McLoone, P., Shephard, S., O'Reilly, S., Kelly, F., may 2019. Shifts in diet of an apex predator following the colonisation of an invasive fish. Hydrobiologia.

doi:10.1007/s10750-019-03972-w

Millar, R. B., Nottingham, C. D., sep 2018. Improved approximations for estimation of size-transition probabilities within size-structured models. Canadian Journal of Fisheries and Aquatic Sciences 0 (ja), null.

doi:10.1139/cjfas-2017-0444 
Milner, N. J., Elliott, J. M., Armstrong, J. D., Gardiner, R., Welton, J. S., Ladle, M., 2003. The natural control of salmon and trout populations in streams. Fisheries Research 62 (2), 111 - 125, the Scientific Basis for Management of Salmonid stocks in the British Isles.

doi:10.1016/S0165-7836(02)00157-1

Minns, C. K., Randall, R. G., Moore, J. E., Cairns, V. W., 1996. A model simulating the impact of habitat supply limits on northern pike, Esox lucius, in Hamilton Harbour, Lake Ontario. Canadian Journal of Fisheries and Aquatic Sciences 53 (S1), 20-34. doi:10.1139/f95-258

Mortimer, C. H., Worthington, E. B., nov 1942. Morphometric data for Windermere. The Journal of Animal Ecology 11 (2), 245.

doi:10.2307/1359

Myers, R. A., Barrowman, N. J., 1996. Is fish recruitment related to spawner abundance. Fishery Bulletin United States 94, 707-724.

Needle, C. L., Jun 2001. Recruitment models: diagnosis and prognosis. Reviews in Fish Biology and Fisheries 11 (2), 95-111.

doi:10.1023/A: 1015208017674

Nilsson, P. A., Brönmark, C., 2000. Prey vulnerability to a gape-size limited predator: behavioural and morphological impacts on northern pike piscivory. Oikos 88 (3), 539546.

doi: $10.1034 / j .1600-0706.2000 .880310 \cdot x$

O'Grady, M., Delanty, K., 2001. A review of changes in the fish stocks of loughs' conn and cullin over time $(1978-2001)$ and recommendations in relation to the long-term management of these lakes and the river moy as salmonid fisheries. Tech. rep., Central Fisheries Board, unpublished report.

Ohlberger, J., Langangen, Ø., Stenseth, N. C., Vøllestad, L. A., 2012. Communitylevel consequences of cannibalism. The American Naturalist 180 (6), 791-801, pMID: 23149403. doi:10.1086/668080

Pace, M. L., Cole, J. J., Carpenter, S. R., Kitchell, J. F., 1999. Trophic cascades revealed in diverse ecosystems. Trends In Ecology \& Evolution 14 (12), 483-488.

doi:10.1016/S0169-5347(99)01723-1 
Patterson, K., Cook, R., Darby, C., Gavaris, S., Kell, L., Lewy, P., Mesnil, B., Punt, A., Restrepo, V., Skagen, D. W., Stefánsson, G., 2001. Estimating uncertainty in fish stock assessment and forecasting. Fish and Fisheries 2 (2), 125-157.

doi: $10.1046 / \mathrm{j} .1467-2960.2001 .00042 . \mathrm{x}$

Pedreschi, D., Mariani, S., Coughlan, J., Voigt, C. C., O’Grady, M., Caffrey, J., KellyQuinn, M., 2015. Trophic flexibility and opportunism in pike Esox lucius. Journal of Fish Biology 87 (4), 876-894.

doi: $10.1111 / \mathrm{jfb} .12755$

Persson, L., Byström, P., Wahlström, E., 2000. Cannibalism and competition in eurasian perch: population dynamics of an ontogenetic omnivore. Ecology 81 (4), 1058-1071. doi:10.1890/0012-9658(2000)081[1058:CACIEP]2.0.C0;2

Plagányi, É. E., Punt, A. E., Hillary, R., Morello, E. B., Thébaud, O., Hutton, T., Pillans, R. D., Thorson, J. T., Fulton, E. A., Smith, A. D. M., Smith, F., Bayliss, P., Haywood, M., Lyne, V., Rothlisberg, P. C., 2014. Multispecies fisheries management and conservation: tactical applications using models of intermediate complexity. Fish and Fisheries 15 (1), 1-22.

doi: $10.1111 / \mathrm{j} .1467-2979.2012 .00488 . \mathrm{x}$

Poole, W. R., Dillane, M., DeEyto, E., Rogan, G., McGinnity, P., Whelan, K., 2007. Sea trout: biology, conservation and management. Blackwell Publishing Ltd, Ch. Characteristics of the Burrishoole Sea Trout Population: Census, Marine Survival, Enhancement and Stock-Recruitment Relationship, 1971-2003, pp. 279-306.

URL http://dx.doi .org/10.1002/9780470996027.ch19

Pope, J. G., 1979. A modified cohort analysis in which constant natural mortality is replaced by estimates of predation levels. ICES C. M. H:16.

Post, J. R., Mushens, C., Paul, A., Sullivan, M., 2003. Assessment of alternative harvest regulations for sustaining recreational fisheries: Model development and application to bull trout. North American Journal of Fisheries Management 23 (1), 22-34. doi $10.1577 / 1548-8675(2003) 023<0022$ : AOAHRF $>2.0 . \mathrm{CO} ; 2$

Prejs, A., Martyniak, A., Boroń, S., Hliwa, P., Koperski, P., 1994. Food web manipulation in a small, eutrophic Lake Wirbel, Poland: effect of stocking with juvenile pike on planktivorous fish. Springer Netherlands, Dordrecht, pp. 65-70.

URL http://dx.doi .org/10.1007/978-94-017-2460-9_6 
Prévost, E., Parent, E., Crozier, W., Davidson, I., Dumas, J., Gudbergsson, G., Hindar, K., McGinnity, P., MacLean, J., Sættem, L. M., 2003. Setting biological reference points for Atlantic salmon stocks: transfer of information from data-rich to sparsedata situations by Bayesian hierarchical modelling. ICES Journal of Marine Science $60(6), 1177-1193$.

doi:10.1016/j.icesjms.2003.08.001

Punt, A. E., Butterworth, D. S., 1995. The effects of future consumption by the Cape fur seal on catches and catch rates of the Cape hakes. 4. Modelling the biological interaction between Cape fur seals Arctocephalus pusillus pusillus and the Cape hakes Merluccius capensis and M. paradoxus. South African Journal of Marine Science 16 (1), $255-285$.

doi:10.2989/025776195784156494

Punt, A. E., Butterworth, D. S., Moor, C. L., De Oliveira, J. A. A., Haddon, M., 2016. Management strategy evaluation: best practices. Fish and Fisheries 17 (2), 303-334. doi:10.1111/faf.12104

Punt, A. E., Hilborn, R., Mar 1997. Fisheries stock assessment and decision analysis: the Bayesian approach. Reviews in Fish Biology and Fisheries 7 (1), 35-63. doi:10.1023/A: 1018419207494

Punt, A. E., Huang, T., Maunder, M. N., 2013. Review of integrated size-structured models for stock assessment of hard-to-age crustacean and mollusc species. ICES Journal of Marine Science 70 (1), 16-33.

doi:10.1093/icesjms/fss185

Quinn II, T. J., Deriso, R. B., 1999. Quantitative Fish Dynamics. Oxford University Press, New York.

Raat, A. J. P., 1988. Synopsis of biological data on the northern pike: Esox lucius Linnaeus, 1758. techreport FIR/S30 Rev. 2, Food and Agriculture Organization of the United Nations, fAO Fisheries Synopsis No. 30 Rev. 2.

Ricker, W. E., may 1954. Stock and recruitment. Journal of the Fisheries Research Board of Canada 11 (5), 559-623.

doi:10.1139/f54-039

Rindorf, A., Cardinale, M., Shephard, S., De Oliveira, J. A. A., Hjorleifsson, E., Kempf, A., Luzenczyk, A., Millar, C., Miller, D. C. M., Needle, C. L., Simmonds, J., Vinther, 
M., 2017. Fishing for MSY: using "pretty good yield" ranges without impairing recruitment. ICES Journal of Marine Science 74 (2), 525-534, handling editor: Emory Anderson.

doi:10.1093/icesjms/fsw111

Sepulveda, A. J., Rutz, D. S., Ivey, S. S., Dunker, K. J., Gross, J. A., 2013. Introduced northern pike predation on salmonids in southcentral Alaska. Ecology of Freshwater Fish 22 (2), 268-279.

doi:10.1111/eff.12024

Sheldon, R. W., Parsons, T. R., 1967. A continuous size spectrum for particulate matter in the sea. Journal of the Fisheries Research Board of Canada 24 (5), 909-915.

doi:10.1139/f67-081

Shephard, S., Delanty, K., O’Grady, M., Kelly, F., nov 2018. Salmonid conservation in an invaded lake: changing outcomes of predator removal with introduction of non-native prey. Transactions of the American Fisheries Society.

doi:10.1002/tafs.10132

Smith, P. A., Leah, R. T., Eaton, J. W., 1996. Removal of pikeperch (Stizostedion lucioperca) from a British Canal as a management technique to reduce impact on prey fish populations. Annales Zoologici Fennici 33 (3/4), 537-545.

Sparre, P., 1991. Introduction to multispecies virtual population analysis. ICES Marine Science Symposium 193, 12-21.

Speirs, D., Guirey, E., Gurney, W., Heath, M., 2010. A length-structured partial ecosystem model for cod in the north sea. Fisheries Research 106 (3), $474-494$.

doi:10.1016/j.fishres.2010.09.023

Sullivan, P. J., Lai, H.-L., Gallucci, V. F., 1990. A catch-at-length analysis that incorporates a stochastic model of growth. Canadian Journal of Fisheries and Aquatic Sciences 47 (1), 184-198.

doi:10.1139/f90-021

Sweeting, C. J., Badalamenti, F., D'Anna, G., Pipitone, C., Polunin, N. V. C., 2009. Steeper biomass spectra of demersal fish communities after trawler exclusion in sicily. ICES Journal of Marine Science 66 (1), 195-202.

doi:10.1093/icesjms/fsn203 
Then, A. Y., Hoenig, J. M., Hall, N. G., Hewitt, D. A., 2015. Evaluating the predictive performance of empirical estimators of natural mortality rate using information on over 200 fish species. ICES Journal of Marine Science 72 (1), 82-92, handling editor: Ernesto Jardim.

doi:10.1093/icesjms/fsu136

Toner, E. D., 1959. Pike in trout waters. Salmon and Trout Magazine 5, 104-110.

Vinther, M., 2001. Ad hoc multispecies VPA tuning applied for the Baltic and North sea fish stocks. ICES Journal of Marine Science 58 (1), 311-320.

doi:10.1006/jmsc.2000.1012

von Bertalanffy, L., 1938. A quantitative theory of organic growth (inquiries on growth laws. II). Human Biology 10 (2), 181-213.

Yodzis, P., 2001. Must top predators be culled for the sake of fisheries? Trends in Ecology \& Evolution 16 (2), 78 - 84.

doi:10.1016/S0169-5347(00)02062-0 